Pasado y Memoria. Revista de Historia Contemporánea,

22, 2021, pp. 53-108

e-ISSN: 2386-4745 | ISSN: 1579-3311

\title{
Napoli e Torino, due rivoluzioni sull'esempio di Cadice
}

\author{
Naples and Turin, two revolutions under the influence of Cadiz
}

Vittorio Scotti Douglas

Università di Modena e Reggio Emilia

https://orcid.org/0000-0002-5075-8624

Recibido: 7-9-2020

Aceptado: 3-12-2020

Cómo citar este artículo / Citation: SCOTTI DOUGLAS, Vittorio (2021). Napoli e Torino, due rivoluzioni sull'esempio di Cadice. Pasado y Memoria. Revista de Historia Contemporánea, 22, pp. 53-108, https://doi.org/10.14198/PASADO2021.22.02

\section{Sommario}

Dopo una breve introduzione sui secolari rapporti tra Spagna e Italia, il saggio presenta un esame sommario della Costituzione di Cadice e si sofferma poi sulla situazione italiana agli inizi della Restaurazione, analizzando in dettaglio e in profondità il caso del Regno delle Due Sicilie e del Regno di Sardegna dal punto di vista politico e sociale, spiegando come la Costituzione di Cadice fosse divenuta la parola d'ordine del movimento patriottico italiano.

Il testo continua indicando come l'insurrezione costituzionale spagnola del 1820 abbia costituito il detonatore della rivoluzione di Napoli dello stesso anno, e mette in luce le reazioni della società napoletana al nuovo regime politico, soffermandosi sul dibattito culturale e politico che si svolse sulla stampa.

Si passa poi alla rivoluzione piemontese, mettendo nuovamente in risalto come l'insieme dei patrioti decidesse di adottare la Costituzione di Cadice dopo molte accese discussioni, e come infine la rivoluzione fallisse da un lato per la condotta pusillanime del Principe Reggente Carlo Alberto, dall'altro per la sostanziale apatia e indifferenza delle classi popolari, che non scorgevano alcun possibile vantaggio materiale immediato in un nuovo sistema politico.

Infine l'Autore, che vuole qui sottolineare l'impiego di una bibliografia basata essenzialmente su fonti contemporanee e di testimoni oculari, conclude l'opera tracciando un parallelo tra patrioti spagnoli e italiani, uniti nel comune destino della lotta per la libertà e l'indipendenza. 
Parole chiave: Costituzione di Cadice; Napoli; Torino; Gugliemo Pepe; Cesare Balbo; Prospero Balbo; Gabriele Pepe.

\title{
Resumen
}

Tras una breve introducción sobre las seculares relaciones entre España e Italia, el presente ensayo ofrece un somero recorrido de la Constitución de Cádiz y se detiene en la situación italiana a comienzos de la Restauración, examinando detenida y profundamente los casos del Reino de las Dos Sicilias y del Reino de Cerdeña desde el punto de vista político y social. Se explica cómo la Constitución de Cádiz se convirtió en la consigna del movimiento patriótico italiano. Se plantea cómo la insurrección constitucional española de 1820 constituyó el detonador de la revolución de Nápoles ese mismo año. Las reacciones de la sociedad napolitana ante el nuevo régimen político, haciendo hincapié en el debate cultural y político reflejado en la prensa, son también objeto de consideración. Respecto a la revolución piamontesa, se muestra cómo, de nuevo, el bando patriota llegó a la decisión de adoptar la Constitución de Cádiz tras encendidas discusiones, y cómo la revolución finalmente fracasó debido a la pusilánime conducta del Príncipe Regente Carlo Alberto y a la sustancial apatía de las clases populares, que no percibían ventaja material inmediata alguna en un nuevo sistema político. Utilizando esencialmente fuentes primarias y testimonios de la época, se establece un paralelo entre los patriotas españoles y los italianos, unidos en el destino común de la lucha por la libertad y la independencia.

Palabras clave: Constitución de Cádiz; Nápoles; Turín; Guglielmo Pepe; Cesare Balbo; Prospero Balbo; Gabriele Pepe.

\begin{abstract}
After a short introduction on the centuries-old relationships between Spain and Italy, this essay offers a brief analysis of the 'Cadiz Constitution', completed with some remarks about Italy at the beginning of the Restoration period, offering a detailed, in-depth study of the kingdoms of Sardinia and the Two Sicilies. A revision of the political and social situation in both states, opens the way to an explanation of how the 'Cadiz Constitution' became the watchword of the Italian patriotic movement. The study shows how the 1820 Spanish constitutional insurrection triggered the Naples revolution that same year. It goes on delving on how the Neapolitan society reacted to the new political regime, emphasizing the cultural and political debate covered by the press. As for the Turin revolution, evidence is offered of how the patriotic faction reached the decision of adopting the 'Cadiz Constitution' only after heated dispute, and also of how the revolution eventually failed. This was due to the coward conduct of the Prince Regent, Carlo Alberto, and the substantial indifference of the low classes, who identified no immediate material advantage in a new political system. Drawing mainly on primary sources as well as on information provided by contemporary eyewitnesses, a parallel is drawn between Spanish and Italian patriots, united in the common destiny of fighting for freedom and independence.
\end{abstract}

Keywords: Cadiz' Constitution; Naples; Turin; Guglielmo Pepe; Cesare Balbo; Prospero Balbo; Gabriele Pepe. 


\section{Lintreccio dei rapporti tra Spagna e Italia}

Benché la storia e la cultura di Spagna e Italia siano strettamente intrecciate da molti secoli, sono stati certamente gli ultimi duecento anni quelli che hanno contribuito a forgiare tra i due Paesi una comunanza di pensiero e di affetti, nutrita da passioni, gioie e dolori condivisi, e cementata anche dal sangue di esuli versato a difesa del superiore ideale di libertà e indipendenza.

Già dagli inizi del XIX secolo, e più precisamente dal maggio del 1808, si stabilisce tra Italia e Spagna un singolare rapporto di ammirazione e di, starei per dire, invidia per il coraggio, la determinazione e, soprattutto, per i successi riportati nella lotta contro l'invasore e occupante francese.

Settant'anni or sono Spini (1990b), e dopo di lui Ferranda Badía (1959)르, avevano chiarito come la Spagna fosse stata sognata e vagheggiata non solo durante le rivoluzioni del 1820-1821, ma già anni prima, come a Torino nel 1812, quando Carlo Vidua trasfondeva nel giovane Cesare Balbo «gli entusiasmi per la resistenza degli spagnuoli contra il despota» (Spini, 1990a: 38-45; Passerin, 1940: 37), o a Milano nel tumulto del 20 aprile $1814^{2}$. Del resto la Spagna tornerà come leit-motiv costante in molti momenti del nostro Risorgimento, dalla richiesta degli insorti napoletani e piemontesi di avere la Costituzione di Cadice del 1812, all'uso generalizzato da un capo all'altro della penisola del nome del generale Quiroga come parola di riconoscimento per i membri di diverse società segrete, dagli Illuminati romagnoli ai Carbonari napoletani e marchigiani ${ }^{3}$.

Fu ancora Giorgio Spini a sottolineare, introducendo l'edizione italiana di Spain 1808-1939 di Raymond Carr (1978), come

«è ovvia l'incidenza sul nostro primo Risorgimento della lotta degli spagnoli contro Napoleone. Persino i termini stessi di «liberale», in contrapposto a «servile», e di «guerriglia» ci vennero dalla Spagna, oltre al modello della

1. Su questi temi Ferrando Badía è poi tornato in altre occasioni $(1962 ; 1987 ; 1991)$.

2. «Il conte Verri dette in Senato una carta, che disse essergli stata posta in mano da persona incognita [...] Alcun senatore [...] vide che [...] esponeva che, come la Spagna e la Germania avevano dato l'esempio, così doveva scuotersi dagli italiani il giogo francese» (Casini, 1897: 18-19).

3. Per gli Illuminati spiegava infatti il delatore Gamberini: «...e difatti dal Budini e dal Pezzi mi furono in seguito insegnati i detti segni [...] per esempio [...] parlando a qualcuno per conoscerlo se è della Società si dice la parola Chirogra e gli deve rispondere Guglielmo Tell». Chirogra è la storpiatura del nome Quiroga (Del Cerro, 1903: 83). Per i Carbonari di Napoli e delle Marche si vedano le rivelazioni di Luigi dell'Uomo del 10 novembre 1820 circa le istruzioni ricevute a Napoli: «...ammaestrandomi che mediante i consueti segni, e la nuova parola, ossia motto d'ordine, che attualmente è CHIROGA-GUGLIELMOTELL, mi sarei facilmente fatto conoscere da tutti i carbonici delle Marche» (Spadoni, 1910: 268). 
Costituzione di Cadice del 1812 ed a quello politico-militare della guerra popolare 'per bande'». (Spini, 1978, I: X)

Anche la curiosità del pubblico sui recenti avvenimenti spagnoli segnalava l'interesse con cui dall'Italia divisa e occupata si guardava alla Spagna che aveva saputo così bene difendere la propria indipendenza e libertà. Considerando solamente Milano e il 1814, vediamo come fossero solerti gli editori a fornire al pubblico una notevole scelta di opere sulla Spagna. Omettendo l'edizione della Costituzione di Cadice, di cui tratterò più avanti, un elenco certo non completo comprende la Risposta al generale francese Lefebvre del generale Palafox, un opuscolo di 75 pagine, Documenti relativi alla storia politica e militare dell'ultima guerra di Spagna, il proclama La giunta suprema del regno alla nazione spagnuola ${ }^{4}$, pubblicato anche a Venezia ${ }^{5}$, e gli Ultimi sforzi della politica di Bonaparte per separare la Spagna dalla coalizione formatasi contro di esso, ossia Manifesto delle Cortes di Spagna sul trattato proposto da Bonaparte nel dicembre $1813^{6}$.

Testimoni di questa curiosità sulle cose di Spagna sono le tempestive traduzioni di ponderose opere sulla guerra d'Indipendenza, la prima delle quali è forse quella pubblicata a Pisa nel 1817, tradotta dall'inglese ${ }^{7}$, ma l'esempio più significativo è l'uscita a Milano nel 1838 -lo stesso anno della prima edizione parigina in spagnolo- dell'opera del Conte di Toreno (Storia, 1817; Toreno, 1838).

\section{La Costituzione di Cadice}

Prima di occuparci dello scenario italiano ove essa esercitò la propria influenza, sono necessarie alcune considerazioni sulla Costituzione di Cadice.

Spostiamoci quindi a Cadice, anzi sull'Isla de León, e precisamente nel Teatro Cómico il 24 settembre 1810. Un oratore si accinge a parlare. Il pubblico si agita, rumoreggia, commenta. Ascoltiamo anche noi.

«-¡Un discurso! Oigamos. ¡Qué ruido en los palcos!

[...]

El discurso no fue largo, pero sí sentencioso, elocuente y erudito. En un cuarto de hora el orador [Muñoz Torrero] había lanzado a la faz de la nación el programa del nuevo gobierno y la esencia de las nuevas ideas. Cuando la última palabra expiró en sus labios y se sentó, [...] el siglo XVIII había

4. Tutte opere edite da Sonzogno.

5. Edita dalla Stamperia Rosa.

6. Per i tipi di Agnelli.

7. Dalla copertina l'opera sembra anonima, tuttavia alla fine dell'introduzione appare il nome dell'Autore, fornito come Giorgio Elliot. 
concluido. El reloj de la historia señaló con campanada, no por todos oída, su última hora, y realizose en España uno de los principales dobleces del tiempo» (Pérez Galdós, 1984: 61).

È di un brano di Cádiz di Benito Pérez Galdós, che rende benissimo l'atmosfera di attesa, di curiosità e di entusiasmo che circondava l'inizio dei lavori delle Cortes e dà inoltre conto, a posteriori, dell'importanza fondamentale delle proposte del deputato Diego Muñoz Torrero, trasformate poi in un decreto che, secondo Calvo Marcos, è «aquel admirable documento, base de nuestro estado político actual y digno de grabarse en bronce y de ser fijada su fecha en el sagrado recinto de nuestras leyes» (1883: 239).

Da quel 24 settembre, in poco più di diciotto mesi, le Cortes discussero ed elaborarono la nuova Costituzione, «la grande obra», promulgata il 19 marzo 1812, giorno di San Giuseppe e perciò subito popolarmente chiamata la Pepa. Essa sanciva la sovranità nazionale, la divisione dei poteri e una decisa limitazione del potere regio. A questo proposito Blanco-White che fu dei difetti della Costituzione uno dei primi e più duri censori ${ }^{8}$, scrisse che «la Constitución española es tan poco mirada en sus precauciones contra el poder Real como la famosa de Suecia» ${ }^{9}$. Altre importanti novità erano che i deputati rappresentavano la Nazione, l'unificazione dei diversi codici per tutto il regno, e in genere una tendenza centralizzatrice, uniformatrice e razionalizzante, in cui si è vista da alcuni una marcata influenza francese (Suárez, 1982: 126).

Come che sia, non c'è dubbio che la Costituzione di Cadice costituisse ai suoi tempi -e ancora oggi- una pietra miliare nella storia di Spagna, e in quella della nuova Europa post-napoleonica ${ }^{10}$. Credo che il vescovo di Mallorca, presidente delle Cortes quel famoso 19 marzo, avesse ben colto l'importanza dell'atto quando concluse il suo discorso di chiusura in modo forse un poco enfatico, ma certo colmo di emozione e sentimento: «¡Ya feneció nuestra esclavitud! Compatriotas míos, habitantes de las cuatro partes del mundo, ¡ya hemos recobrado nuestra dignidad y nuestros derechos! ¡Somos españoles! ¡Somos libres!» (Suárez, 1982: 122).

8. La posizione di Blanco-White è stata illustrata da Moreno Alonso (1989: 521-543; 1984 : 65-106). È anche importante Pons (1992). Larticolo è il sommario di alcuni capitoli della ponderosa tesi dell'Autore (Pons, 1990). La tesi è stata tradotta in spagnolo e pubblicata in tre volumi:(Pons, 2002, 2006, 2010). Da ultimo, e di particolare interesse per il nostro argomento, l'articolo di Varela (1993). A proposito di Blanco White ricordiamo che presso l'editore Almed di Granada è in corso dal 2005 la pubblicazione delle Obras completas a cura di Antonio Garnica Silva. I primi volumi sono stati dedicati ai periodici, ossia al Semanario patriótico (Siviglia, 1809), e all' Español.

9. El Español, V, 25, mayo de 1812, Breves reflexiones sobre algunos artículos de la Constitución española que precede, 79.

10. Per una rassegna delle critiche di parte liberale si veda il saggio di Suárez (1987). 


\section{L'Italia dei primi anni della Restaurazione}

Se ora si considera l'Italia di qualche anno dopo, troviamo un'atmosfera ben diversa da quella trasmessa dalla chiusa del discorso del reverendo Bernardo Nadal y Crespí. Triste paese infatti era l'Italia dei primi anni della Restaurazione, né facevano eccezione gli Stati, come il Piemonte sabaudo, usciti territorialmente accresciuti dal Congresso di Vienna, né quelli, come il regno di Napoli e di Sicilia, restituiti, tra il giubilo in gran parte sincero dei sudditi, ai governi (o meglio, alle dinastie) di prima della grande Rivoluzione. Triste, s'intende, per coloro che nel periodo rivoluzionario e napoleonico si erano battuti per gli ideali di libertà e uguaglianza che venivano di Francia, e per chi, nato e cresciuto in quegli stessi anni, era venuto maturando il sentimento nazionale italiano.

Anche se la storiografia italiana più recente è concorde nell'affermare che la Restaurazione non fu una pura e semplice reazione e nemmeno un ritorno all'Ancien régime (Candeloro, 1956-1986: II, 13; Salvatorelli, 1962: 76-77) ${ }^{11}$, né per la sistemazione dinastica e territoriale o per la struttura interna degli Stati italiani, né per l'apparato legislativo, amministrativo, finanziario e militare, ove si ebbe quasi sempre il permanere in servizio di gran parte del personale dell'epoca napoleonica, tuttavia il ritorno a un sistema assolutistico-riformatore fortemente accentrato non poteva che generare un diffuso malcontento.

Giocava in esso anche un elemento di carattere psicologico, giacché il periodo napoleonico veniva visto come un'epoca eroica, sostanzialmente progressista e fortemente positiva, mentre, soprattutto per i giovani più aperti ai nuovi fermenti romantici, il presente appariva meschino, grigio, uniforme e senza prospettive di carriera e di successo.

Il malcontento era poi aggravato dalla cristallizzazione della situazione sociale esistente, in cui spiccava il netto prevalere della nobiltà e della grande borghesia terriera. Gli alti gradi della diplomazia, della burocrazia, delle forze armate e della Corte furono appannaggio della nobiltà, strettamente alleata con la Chiesa; così il desiderio di innovazione e di progresso della borghesia industriale e mercantile, dello strato più intraprendente della piccola borghesia e del nascente proletariato urbano, venne frustrato dalla classe nobiliare, che riuscì nel contempo a legare a sé la borghesia terriera più ricca. La maggior parte della terra rimase perciò in mano ai nobili, che, grazie ai rapporti di

11. Soprattutto Maturi (1969, I: 72): «La restaurazione in Italia non fu una reazione, ma fu (come dire?) una terza edizione del dispotismo illuminato, indebolito moralmente, intellettualmente e praticamente». 
produzione agrari -ancora cristallizzati in forme feudali o semi-feudali- continuarono a esercitare sui contadini un gravoso dominio economico e morale.

La situazione di stasi politica e quindi di freno della crescita della borghesia, venne altresì favorita, fin quasi al 1820, da fattori esterni sia di indole economica, come la carestia, col conseguente forte rialzo dei prezzi dei prodotti agricoli, e il crollo di quelli dei prodotti industriali, causato dalla crisi di sovrapproduzione dell'industria britannica; sia di natura psicologica, come la grande stanchezza e il generale desiderio di tranquillità generati in tutta Europa dal lungo susseguirsi delle guerre napoleoniche $e^{12}$.

Ma questa situazione non poteva durare, e fu proprio il pronunciamiento di Riego e Quiroga a fungere da detonatore e a fornire ai patrioti italiani più rivoluzionari la parola d'ordine e il programma per cui insorgere e lottare: la Costituzione del 1812.

Già prima della Rivoluzione francese, e subito dopo la sua esplosione, erano stati elaborati in Italia dei progetti di Costituzione con lo scopo di dare una rappresentanza più equa ai nuovi ceti emergenti e una certezza ai rapporti di proprietà ${ }^{13}$. Mi riferisco al progetto del Granduca Pietro Leopoldo I di Toscana del 1781, e a quello di Pietro Verri del 1790, le cui idee in parte si possono ritrovare nella supplica dello stesso anno all'imperatore Leopoldo II da parte dei nobili lombardi per una rappresentanza che non fosse solo dei consigli patrizi ${ }^{14}$. Erano però costruzioni concettuali astratte che non entrarono mai nel gioco della dialettica e della polemica politica.

12. Per mostrare come la carestia fosse generalizzata in tutta Italia, citeremo testimonianze da differenti regioni. Per il Lombardo-Veneto il delegato di Como segnalava nell'agosto 1816 il ritrovamento di un uomo «morto d'inedia in uno dei comuni della provincia. Questo fatto [...] potrebbe da solo provare lo stato di miseria di alcune parti della provincia; in quest'anno ogni genere di raccolto andò perduto [...], a segno che li contadini, consunti che abbiano li pochi legumi e le castagne, il cui raccolto pure è scarso, resteranno ben presto privi dei mezzi di sussistenza», Archivio di Stato di Como, Fondo Prefettura, c. 2081, Lettera del delegato Provinciale al Consiglio di Governo, 27 agosto 1816; per il Granducato di Toscana: «...squallidi e macilenti tapini s'incontravano per le vie cibandosi d'erbe selvatiche [...] e talora le carni d'animali immondi servivan loro di scarso pasto [...]. Spirarono alcuni l'anima [...] nelle pubbliche strade, vittime della fame e del gelo» (Zobi, 1852, IV: 176-177). Vedi anche Marcotti (1907).

13. Sulle costituzioni italiane prima di Cadice si veda ora Trampus (2015).

14. Il progetto di Pietro Leopoldo: Estratto della Costituzione imaginata e sbozzata regnante Leopoldo I a reintegrazione de' diritti nazionali, fu pubblicato per la prima volta da Zobi (1852: 63-71). Il testo era già noto per almeno due edizioni precedenti, ambedue anonime, la prima del 1832 priva di editore e di luogo di pubblicazione, Memorie sulla costituzione di governo immaginata dal Gran-Duca Pietro Leopoldo Primo da servire alla storia del suo regno in Toscana; la seconda del 1847, La Costituzione toscana immaginata dal Granduca Pietro Leopoldo Memoria del senatore F.M. Gianni Scritta nell'Anno 1805, Italia, 1847. Uscì poi in Tabarrini (1877, II: 407-414) e Lettera sulla costituzione di Pietro 
Durante il periodo rivoluzionario e poi sotto la dominazione napoleonica gli italiani avevano invece conosciuto molte Costituzioni, alcune semplici copie delle francesi, altre -come quella concepita nel 1799 da Mario Pagano per la Repubblica Partenopea- elaborate in modo originale da illuminati pensatori nostrani. Ma anche se gli statuti di elargizione napoleonica erano più moderni e razionali degli antichi, però comune era il voluto difetto di fondo, confermato dalla dichiarazione di Napoleone a Metternich: «Non concederò mai agli italiani un sistema liberale; ne ho concesso loro soltanto un simulacro».

Bisogna poi citare la Costituzione di Bayona (Busaall, 2015), promulgata da Giuseppe Bonaparte il 20 giugno 1808 per il Regno di Napoli e di Sicilia, mai applicata, e soprattutto prendere in esame quella siciliana del $1812^{15}$, dovuta ai principi di Belmonte e di Castelnuovo e all'abate Balsamo, imposta al re Ferdinando dai baroni dell'isola col forte appoggio del plenipotenziario inglese lord William Bentinck, che rispose alla forte opposizione della regina Carolina con la celebre frase: «Madama, non vi è via di mezzo: o Costituzione o Rivoluzione» (Gualterio, 1861, IV: 138) ${ }^{16}$. Era un testo di difficile comprensione e applicazione, ma aveva molti pregi, non ultimo quello di essere estremamente liberale senza arditi proclami democratici né violente opposizioni all'autorità regia. Infatti essa riservava al Parlamento, composto da una Camera dei Pari e da una dei Comuni, il potere di fare, interpretare, modificare e abrogare le leggi, concedendo al monarca il solo potere sanzionatorio con le formule placet o veto. La Camera dei Pari era per i nobili o per chi godesse di una fortissima rendita fondiaria. Il fatto che la Costituzione siciliana costituisse, in certo modo, il testo scritto di quella inglese, fece sì che alcuni patrioti

Leopoldo scritta nel 1847, (415-421). Anche Guardione (1927). La trattazione più recente è di Manetti (1991). Per il progetto di Pietro Verri: Pensieri sullo stato politico del Milanese nel 1790, il testo si trova in Verri (1854, II, Appendice: 1-36). Per un inquadramento e considerazioni più approfondite si veda Meriggi (1981); Sella; Capra (1984: 598-602); Capra (1989). Per la supplica a Leopoldo II si veda Archivio di Stato di Venezia, Dispacci ambasciatori Milano, filza 237, dispaccio 267 di Andrea Alberti, 30 giugno 1790.

15. Costituzione del Regno di Sicilia proposta dal Generale Straordinario Parlamento del 1812. Sanzionata con due Reali Diplomi de' 9 Febbraio e 15 Maggio 1813, Palermo, Reale Stamperia, 1813. Ne esiste almeno un'altra edizione Costituzione di Sicilia stabilita nel generale straordinario Parlamento del 1812. Preceduta da un discorso sulla medesima, e da' diplomi relativi alla Convocazione del Parlamento, ed alla sanzione di tutte le proposte di esso: Coll'aggiunta di un Compendio della Costituzione d'Inghilterra, Palermo, Solli, 1813.

16. Su lord Bentinck e la Sicilia (Aceto, 1827; Bianco, 1902; Capograssi, 1949; J. Rosselli, 1956; Renda, 1963). Sull'occupazione inglese e la Costituzione isolana si veda il vecchio studio di Titone (1936). Sulla Costituzione siciliana è ora fondamentale il volume di Romano (1998), e il suo ricco apparato bibliografico. Vi si trova ad esempio il saggio di Portillo (1998). Ricordo poi gli studi più recenti: (D'Andrea, 2007; 2012). Va poi tenuto presente (anche per Napoli) il volume di Daum (2007). Da vedere anche il recente contributo di De Salvo (2016). 
moderati, come Santorre di Santarosa, preferissero il testo siciliano, modificato e sfrondato dell'eccessivo apparato regolamentare ${ }^{17}$.

Altra cosa era la Costituzione di Cadice, che fin dal momento della proclamazione molto interesse ed entusiasmo aveva suscitato in Italia, come è provato dalla precocità, dal numero e dalla diffusione territoriale delle traduzioni ${ }^{18}$. Nel 1813, ed è la prima traduzione in assoluto in un'altra lingua, compare a Messina per i tipi di Giovanni del Nobolo, stampatore -fra l'altro- dell'ufficiale Gazzetta Britannica ${ }^{19}$, la Costituzione politica della monarchia spagnuola. Tradotta dall'originale ${ }^{20}$. Lanno dopo la Costituzione spagnola viene pubblicata a Milano $^{21}$, Piacenza ${ }^{22}$ e Roma ${ }^{23}$; esce in francese a Parigi ${ }^{24}$.

Nonostante l'abbondanza delle traduzioni è da ritenere che la conoscenza del testo della Costituzione di Cadice fosse piuttosto scarsa, se non addirittura inesistente, come è provato dall'urgenza di provvedere alla traduzione in cui si trovarono gli insorti tanto a Napoli nel $1820^{25}$ come a Torino nel $1821^{26}$. La

17. Alla semplificazione della Costituzione siciliana si dedicò appunto Santarosa in esilio a Parigi, e la pubblicò nel 1822, in appendice alla terza edizione di De la révolution piémontaise Troisième édition, revue, corrigée et augmentée de notes et de l'analyse de la constitution sicilienne, Paris, Alexandre Corréard.

18. Sulle varie edizioni italiane della carta gaditana si veda ora, oltre a quanto esposto nel testo, Luseroni (2015).

19. Su questo interessante periodico pubblicato a Messina dal 1808 al 1814 si veda innanzitutto Spini (1958; 1990a). Da vedere anche (D’Angelo, 1998; De Salvo, 2009; 2010). La stessa De Salvo, dopo una lunga ricerca in biblioteche italiane ed europee, è riuscita a ricostruire una collezione sostanzialmente completa della «Gazetta Britannica», ora disponibile on line sul sito http//www.ars.sicilia.it/biblioteca/gazzetta/gazzetta.jsp nella sezione Opere di pregio.

20. Costituzione politica della monarchia spagnola, Messina, Giovanni Del Nobolo (impressore britannico), 1813. Ne esiste ora un'edizione facsimilare: Soveria Mannelli, Rubbettino, 2000 con nota introduttiva di Romano (Cadice come modello costituzionale per l'Europa liberale e antinapoleonica) e la versione italiana del saggio di Muñoz De Bustillo (2002).

21. Costituzione politica della Monarchia Spagnuola promulgata in Cadice il 19 marzo 1812, Milano, Sonzogno e Compagni, 1814.

22. Costituzione politica della monarchia spagnuola promulgata in Cadice il 19 marzo 1812, Piacenza, Ignazio Orcesi, 1814. Ė identica all'edizione di Sonzogno, anche nel decreto delle Cortes, ma senza l'avviso Al pubblico.

23. Costituzione politica della monarchia spagnuola promulgata in Cadice nel marzo del 1812. Preceduta da tre lettere preliminari colle quali gli estensori di essa la diressero alle corti. Tradotta in italiano da Juan Francisc Masdeu barcellonese, Roma, Stamperia L. Perego Salvioni, 1814.

24. È il testo di cui si servì il famoso reazionario svizzero Haller per la sua violenta critica alla carta gaditana.

25. Costituzione politica della monarchia spagnuola tradotta per ordine del governo. Ed. uffiziale, Napoli, L. Nobile, 1820.

26. Costituzione politica Spagnuola, promulgata in Cadice il 19 di marzo 1812, Torino, Stamperia reale, 1821. 
storia della traduzione e della tentata pubblicazione a Lucca, interessante e in certo modo curiosa, esula dall'argomento di questa esposizione ${ }^{27}$.

Annibale Alberti, insigne studioso delle assemblee italiane pre-unitarie, ha sostenuto, in un saggio premesso alla raccolta degli Atti di quelle assemblee, che:

«Le Costituzioni del Risorgimento [...] furono mezzo non fine. Per esse si venne rafforzando il principio di nazionalità e si venne svolgendo la personalità delle varie regioni italiane unite per la lingua, per le tradizioni, per le tendenze, ma forzatamente divise dalla tirannia straniera [...]» (Alberti, 1911, I: CLIX).

E prosegue dicendo:

Nemmeno i popoli $[\ldots]$ si preoccuparono della sostanza delle Costituzioni: era la Costituzione in tesi generale che si voleva, perché questa significava opposizione viva e perenne agli ordini precedenti» (Alberti, 1911, I: CLXI).

Questa affermazione, dopo rigorose valutazioni fatte a posteriori, contiene certamente molti elementi di verità. Non c'è dubbio, però, che nel 1820, per parafrasare un testo ben conosciuto, «uno spettro si aggirasse per l'Europa»: quello della Costituzione di Cadice. Le reazioni delle diverse potenze furono significative; anche se solamente la Russia espresse il proprio dissenso, chiedendo l'intervento armato della Santa Allenza per riportare l'ordine in Spagna ${ }^{28}$, tutti gli altri governi mantennero un riserbo discreto e accigliato che solo la sprovveduta e ottimista diplomazia del ministero Argüelles e del ministro degli esteri, Evaristo Pérez de Castro (Spini, 1990b: 49-52, 84-86, 121), poté interpretare come favorevole al mutamento istituzionale e illudersi che rimanere indifferenti e passivi nei confronti di quanto accadeva in altri Paesi sarebbe bastato a escludere l'intervento della Santa Alleanza.

Ciò che politicamente spaventava le Corti europee, e soprattutto Vienna e Mosca, -senza prescindere dal fatto che la Costituzione era stata imposta con una sollevazione militare- era il carattere apertamente democratico della Carta di Cadice, con la proclamazione della sovranità popolare e della libertà di stampa, e con il ruolo subalterno alle Cortes riservato al monarca. Gli ambienti più conservatori legati all'alta nobiltà e al clero, in tutta Europa come anche in Spagna, non potevano vedere di buon occhio un Parlamento monocamerale elettivo, in cui, almeno teoricamente, non era possibile far valere privilegio

27. Per le vicende della Costituzione spagnola a Lucca (Sforza, 1921; Spini, 1990b: 60-64). 28. Per la risposta del ministro degli Esteri russo, principe Nesselrode, alla comunicazione del governo spagnolo sull'avvenuta proclamazione della Costituzione (Farini, 18541859, II: 106-107). 
alcuno. Per converso era proprio questo carattere rivoluzionario ed eversivo, genericamente conosciuto e sussurrato in tutte le riunioni settarie, a farne lo stendardo e la meta di ogni progetto cospirativo italiano ${ }^{29}$.

Ma quale era, al momento del pronunciamiento di Cadice del gennaio 1820, la situazione negli Stati italiani su cui esso e la Costituzione del 1812 avrebbe agito come detonatore?

Prima di questa analisi, vorrei sottolineare un carattere -a mio parere molto importante- delle rivoluzioni di cui mi occuperò, che può sembrare, a prima vista, diminuirne la portata e la rilevanza, ma che secondo me invece le accresce.

Come sappiamo, e come in modo sprezzante scrisse Metternich, ambedue i tentativi rivoluzionari furono rapidamente sconfitti e seguiti da una feroce repressione. Tuttavia una lucida osservazione del patriota molisano Gabriele Pepe, dal 1823 in esilio a Firenze per la partecipazione ai fatti del 1820 e 1821, rafforza l'opinione che sto per esprimere.

A Firenze tra il 1827 e il 1828 Pepe scrisse le Considerazioni Istoriche e Politiche sulla Rivoluzione Napoletana (Pepe, 1978) ${ }^{30}$, opera importante per l'acutezza dell'analisi della rivoluzione di cui si studiano le motivazioni più remote con una disamina del decennio francese e il susseguente quinquennio borbonico, passando poi in rassegna le società segrete, l'esercito, e l'insieme della società.

Ragionando sul fatto che «la rivoluzione napoletana resse nove mesi e finì male», Pepe ribatteva: «Il giudicar però dal successo benché sia il metodo più certo relativamente al fatto, è sovente il più fallace per determinare la vera $\mathrm{e}$ giusta entità del fatto istesso» (Pepe, 1978, I: 47).

Questi «moti» sconfitti -così chiamati in passato per sminuirne l'importanza- sono gli ultimi rivolgimenti «vecchi», organizzati secondo gli schemi tradizionali delle «sette», come venivano allora chiamate le società segrete. Modo ormai sorpassato di fare politica, modelli organizzativi pieni di rituali, simboli, formule a metà tra il magico e il superstizioso, giuramenti col sangue e col fuoco, un armamentario farraginoso, che oggi appare (ma già appariva allora a chi cominciava a fare politica), francamente ridicolo e anche pericoloso.

Dopo il 1820-21 tutto cambia, le società segrete tramontano, si afferma qualcosa di nuovo, una struttura che possiamo a buon diritto considerare il

29. Con riferimenti specifici a come venne recepita nei diversi Stati italiani la Costituzione di Cadice si vedano (De Francesco, 1996; Colombo, 1998; Romano, 2004; 2015).

30. Su Pepe si veda il saggio (Scotti Douglas, 2009), per le vicende di Gabriele Pepe durante la rivoluzione le pp. 101-102 e le note relative. Per un trattamento più diffuso delle opinioni di Pepe sulla rivoluzione si veda (Scotti Douglas, 2015: 510-519). 
primo partito politico moderno italiano, e forse europeo, ossia la Giovine Italia mazziniana.

Perché allora dico che proprio la loro origine «settaria»-fu la Carboneria il motore della rivoluzione napoletana, e i Federati di quella piemontese- accresce l'importanza di questi moti? Perché la nascita nel clima oscuro e ambiguo della congiura sussurrata, tra simboli e segnali astrusi di riconoscimento, non impedì loro di affermarsi e diventare -soprattutto nel Napoletano, dove ebbe più tempo per svilupparsi e crescere- vero movimento di popolo in cerca del riscatto. E questa è «la vera e giusta identità del fatto» citata da Gabriele Pepe.

Dicendo questo ho un illustre precedente. Infatti un grande storico cattolico e moderato, Luigi Salvatorelli, ha affermato in un testo ormai classico, Pensiero e azione nel Risorgimento, che:

«I moti del '20 e '21 in Italia furono la prima vera iniziativa rivoluzionaria del Risorgimento, poiché i rivolgimenti alla fine del secolo XVIII erano avvenuti in seguito e in forza dell'intervento francese. [...] Italianità ed europeismo furono strettamente associati in quei moti [...]. Il problema italiano si pose come questione europea innanzi ai governi delle grandi potenze» (Salvatorelli, 1963: 85).

Passiamo ora all'analisi della situazione nei due Stati italiani nel periodo della Restaurazione, guardando prima al Regno di Napoli poi al Piemonte sabaudo.

\section{Il regno di Napoli durante la Restaurazione}

Nel regno delle Due Sicilie ${ }^{31}$ il processo della Restaurazione era stato fissato con rigidità dal trattato di Casa Lanza del 20 maggio 1815 e dai due trattati austro-borbonici del 29 aprile e 12 giugno dello stesso anno. Questi atti tendevano a impedire che i Borboni scatenassero una repressione come quella del 1799 , li impegnavano a non perseguitare chi aveva servito i francesi e Murat e a garantire i patrimoni formatisi in seguito alle riforme del decennio precedente. Il punto fondamentale che stava a cuore al governo di Vienna era sancito da un articolo segreto del trattato di alleanza con l'Austria del 12 giugno che impegnava il governo napoletano a non introdurre modifiche istituzionali in

31. Così trasformato da «Regno di Napoli e Sicilia» grazie all'ambasciatore napoletano a Vienna, Alvaro Ruffo, che fece astutamente tradurre il testo francese dell'articolo 104 dell'Atto finale del Congresso di Vienna, che si limitava a parlare di Roi des Deux Siciles, in Re del Regno delle Due Sicilie, senza che alla formula obiettassero gli altri firmatari dell'atto. Si creava così una formazione statale nuova, in palese contrasto con l'articolo 8 della Costituzione siciliana del 1812 e con la precedente tradizione giuridica del Regno di Sicilia. 
senso costituzionale ${ }^{32}$. Questo era perfettamente consono al modo di sentire di Ferdinando I, uomo volgare e ignorante, pur se non privo di una certa perspicacia (Croce, 1965: 205, 239-240), che dopo essersi alienato con i massacri del 1799 la parte migliore della società napoletana -entrata compattamente nel movimento liberale- ebbe tuttavia l'accortezza di affidare la guida del governo a un abile e preparato assertore dell'assolutismo amministrativo, Luigi de' Medici.

Medici, per ottenere la collaborazione dei molti funzionari e ufficiali rimasti murattiani, svolse la cosiddetta politica dell' «amalgama», che tendeva a unificare in un solo gruppo dirigente gli uomini che avevano seguito il re nell'esilio in Sicilia con i murattiani. Anche nei confronti della Carboneria Medici fu prudente, evitando la repressione violenta, al punto da scontrarsi duramente col principe di Canosa, ministro di polizia, fautore delle maniere forti e sostenitore della setta reazionaria dei Calderari. Nel tentativo, poi, di ingraziarsi i piccoli possidenti agrari, Medici nel 1817 ricostituì le milizie provinciali, contribuendo così in modo imprudente ad armare proprio la gran massa di coloro che tanto avevano da dolersi del suo governo. Complessivamente, l'opera di Medici fu di conservazione delle riforme introdotte nel Decennio e anzi, per quanto riguarda la Sicilia, addirittura di progresso. Ma nell'isola le riforme vennero calate dall'alto e dall'esterno, stimolando in tal modo l'indipendentismo, che si nutriva anche del ricordo della propria Costituzione del 1812, prima violata con la creazione del regno delle Due Sicilie e poi di fatto abolita col decreto dell'11 dicembre 1816. Perciò, pur senza eccessi repressivi né manifestazioni particolarmente reazionarie, tuttavia l'azione del governo Medici ebbe un carattere nettamente conservatore, ossia, come dice Giorgio Candeloro «di sostanziale indietreggiamento rispetto alla spinta progressiva impressa al Regno dalle riforme del Decennio e in una certa misura anche rispetto allo stesso illuminismo riformistico» (Candeloro 1956-1986, II: 69).

Latteggiamento governativo aveva quindi già di suo causato un diffuso malcontento, che venne grandemente accresciuto dalla carestia del 1817 e dalla conseguente pesantissima crisi agraria innescata dall'importazione a prezzi

32. Larticolo diceva: «Les engagements que Leurs Majestés prennent par ce traité pour assurer la paix intérieure de l'Italie, leur faisant un devoir de préserver leurs Etats et sujets respectifs de nouvelles réactions, et du danger d'imprudentes innovations qui en améneraient le retour, il est entendu entre les hautes Parties contractantes, que S.M. le Roi des Deux Siciles, en rétablissant le Gouvernement du Royaume, n'admettra pas de changemens qui ne pourraient se concilier soit avec les anciennes institutions monarchiques soit avec les principes adoptés par S.M. I. et R. Apostolique pour le régime intérieur de ses provinces italiennes» (Gualterio, 1861, I: 170-171). Se ne veda il testo italiano in Bianchi (1865, I: 207-208). 
bassissimi di grano dalla Crimea. Osservava Luigi Blanch, storico napoletano contemporaneo:

«La quantità di cereali, di cui le coste del Mar Nero [...] inondavano i mercati delle provincie del Mezzogiorno dell'Europa, rompeva nel suo centro tutto il sistema economico delle nazioni agricole [...], con alterare tutte le proporzioni delle spese di cultura e delle imposte col prodotto netto che restava ai proprietari. Questi, obbligati $[\ldots]$ a diminuire le loro spese, facevano [...] risentire questi effetti alle classi inferiori, di cui diminuivano il benessere, [...]. Questa rivoluzione $[\ldots]$ aveva naturale tendenza ad accusare il potere di contribuire al male con la gravità dei pesi che imponeva; il che disponeva gli animi a desiderare $[\ldots]$ un mezzo di conoscere e di limitare le spese del governo e di scaricarne i contribuenti. » (Blanch, 1945, II: 305-306).

Considerazioni analoghe faceva il 20 luglio 1820 l'autorevole economista Melchiorre Delfico, aggiungendo poi un'acuta osservazione sugli errori del governo che creava il desiderio di un cambio politico e la forza per eseguirlo armando le milizie provinciali, e così concludeva: «Non si fa bene il Ministro senza ben conoscere gli amministrati» (Delfico, 1820: 15).

Non c'è quindi da meravigliarsi del fatto che, approfittando della favorevole congiuntura, la Carboneria divenisse il punto d'incontro e di raccolta di tutti i malcontenti, soprattutto nelle province. Cito ancora Candeloro:

«Era largamente diffusa tra i piccoli possidenti, i professionisti, i mercanti, gli artigiani; penetrava nel basso clero; aveva numerosi adepti tra i sottufficiali e gli ufficiali subalterni dell'esercito e più ancora nelle milizie provinciali [...]; sembra perfino che in certe zone penetrasse anche tra i contadini, i quali comunque non erano estranei alla sua influenza». (Candeloro, 1956-1986, II: 72).

Sul numero degli aderenti le valutazioni sono diversissime e contrastanti; si va da un minimo di duecentomila, già ritenuto esagerato da Luigi Palma (1895), fino all'affermazione del giornale napoletano «L'Amico della Costituzione» del 23 luglio 1820 «che in marzo di quest'anno i Carbonari iscritti erano al numero di 642 mila», giustificato solo comprendendovi tutti gli appartenenti alle cosiddette «classi basse» che condividevano gli obiettivi della Carboneria.

Il programma dei Carbonari non era chiaro, né aveva un preciso indirizzo ideologico; richiesta fondamentale era precisamente quella della Costituzione spagnola del 1812, pochissimo conosciuta nei particolari, ma ritenuta migliore della siciliana dello stesso anno o della francese del 1814, e utilizzata come strumento d'intimidazione nei confronti del governo. Infatti nell'autunno del 1817 si inviarono al re e ai ministri «copie della costituzione delle Cortes» 
(Manfredi, 1932: 6) ${ }^{33}$ e si fecero affiggere manifesti, in cui «si chiedeva al re una Costituzione, e si eccitava il popolo a non pagare le tasse nel caso di un rifiuto» (Dito, 1905: 236). D'altro canto molti alti ufficiali dell'esercito di provenienza murattiana, tra cui spiccava il tenente generale Guglielmo Pepe, pur non aderendo alla Carboneria, erano in stretto contatto con essa e pienamente informati dei suoi piani insurrezionali, che speravano di controllare secondo i propri intendimenti (Pepe, 1847, I: 340-360).

Così, negli anni dal 1817 al 1820, in mezzo al malcontento crescente e all'infittirsi delle trame cospirative, per tutte le province di terraferma del Regno delle Due Sicilie andava crescendo la rivendicazione patriottica dei Carbonari, estrinsecata nella richiesta della Costituzione di Cadice.

\section{Lo Stato sabaudo durante la Restaurazione}

Se si eccettua il Ducato di Modena, dove Francesco IV d'Austria-Este tornò alla legislazione settecentesca e impresse al governo uno spiccatissimo carattere reazionario, non v'è dubbio che il Piemonte sabaudo sia stato quello, tra gli Stati italiani, in cui la Restaurazione fu più vicina all'ideale degli scrittori retrivi, anche perché -abrogati i codici napoleonici- si tornò alla legislazione prerivoluzionaria, che assai poco aveva risentito dei benefici effetti del riformismo illuminato per la scarsa influenza che questo aveva avuto in Piemonte. Recitava infatti l'editto del 21 maggio 1814 -che secondo un testimone del tempo "parve a tutti provvidenza non solamente insolita ma mostruosa» (Sauli, 1908: 310)che «non avuto riguardo a qualunque altra legge, si osservassero da quella data le regie costituzioni del 1770 e le altre provvidenze emanate sino all'epoca del 23 giugno $1800 »$. Se a ciò si aggiunge che nei primi anni dopo il 1814 vennero accantonati o posti in posizioni subordinate tutti coloro -nobili e borghesi, prevalentemente giovani e capaci- che avevano servito i Francesi, mentre in tutti i campi -nella politica, nell'amministrazione, nell'esercito- le cariche più importanti si affidavano a chi aveva seguito il re in esilio o era rimasto in disparte durante l'occupazione, persone quasi sempre in età avanzata, di mentalità retriva e di scarsa preparazione, si vedrà come nel Regno il ritorno al passato fosse molto incisivo, e in stridente contrasto con la situazione dei Paesi confinanti, non solo Francia e Svizzera, ma persino con la Lombardia austriaca.

La libertà di pensiero conobbe gravi limitazioni: si restrinse la libertà di culto a valdesi ed ebrei, fu sciolta e proibita la Massoneria, si riaccolsero con entusiasmo i gesuiti, l'istruzione venne praticamente abbandonata ai diversi

33. Anche Memorie sulle società segrete (1904: 83-84). 
ordini religiosi; insomma, come dice efficacemente Candeloro, «si stese su tutto il Regno una pesante atmosfera di bigotteria» (Candeloro, 1956-1986, II: 43).

Simile fu l'organizzazione della vita economica, con la creazione di barriere doganali interne, con il ristabilimento di una forte legislazione vincolistica e l'imposizione di proibitivi dazi di importazione ed esportazione. Tutto ciò ebbe come ovvio effetto il rallentamento dei traffici e pesò anche sullo sviluppo del porto di Genova, che pure si trovava in condizioni assai favorevoli per diventare lo sbocco al mare non solo della nuova entità statale di cui faceva parte, ma anche di buona parte della Lombardia.

Il re Vittorio Emanuele I era un personaggio rigidamente assolutista, completamente privo di senso della storia: «Ho dormito quindici anni, ripeteva spesso, ora mi sono svegliato e non ho che a ripigliare le cose del giorno avanti» (Brofferio, 1849, I: 94), meritandosi così la secca risposta («acerba» la chiama Brofferio) dell'ambasciatore russo principe Kozlovsky che disse al sovrano: «Sire, ringraziamo il cielo che non abbia dormito anche l'imperatore di Russia, altrimenti Vostra Maestà correva gran rischio di non risvegliarsi sul trono» (Brofferio, 1849, I: 94-95) ${ }^{34}$. Il re era totalmente contrario alle benché minime innovazioni istituzionali, che pure -nella forma della Charte octroyée di Luigi XVIII- sarebbero state molto gradite in funzione anti-austriaca dalla Francia e dalla Russia, che esercitarono in tal senso forti pressioni sul governo sabaudo, utilizzando sia i tradizionali canali diplomatici sia addirittura agenti segreti in contatto con gli ambienti di Corte, ma anche con i gruppi liberali e le società segrete. Questi sforzi in realtà furono controproducenti, anche se nel Regno sabaudo era vivo e sentito un forte sentimento anti-austriaco, che giocò in senso favorevole al diffondersi delle idee liberali e patriottiche. Questo sentimento era un altro elemento che univa il popolo al monarca, che una volta, parlando con uno dei suoi ufficiali, il futuro cospiratore Giacinto Provana di Collegno, esclamò: «Non vi sarà mai nessuno che mi libererà da questi fottuti di tedeschi?» (Collegno, 1929) 35 .

La diffusione delle idee liberali era tuttavia resa più difficile in Piemonte dal fatto che il cattolicesimo reazionario si era dato un'organizzazione pubblica,

34. Il principe Piotr Borisovic Kozlovsky (1783-1840), fluente in molte lingue, entrò in diplomazia nel 1801 e nel 1802 fu nominato interprete della missione russa presso il Regno di Sardegna e seguì la corte nell'esilio di Cagliari. Incaricato d'affari nel 1810, l'anno dopo tornò brevemente in Russia, e nel 1812 venne nominato ambasciatore alla corte sabauda, ove rimase fino al 1816. Ebbe poi incarichi in diversi Paesi europei ma, caduto in disgrazia per le sue posizioni liberali, nel 1820 si dimise, pur continuando a girare l'Europa. Tornò in Russia nel 1835 e rientrò nel servizio diplomatico. Morì a Baden-Baden.

35. Si vedano anche (Ottolenghi 1882: 19; Ricotti, 1856: 374). 
l' «Amicizia cattolica», formata da laici, dotata di organi di stampa e di una notevole influenza sui ceti dirigenti ${ }^{36}$. Le si opponevano, ma non in modo organizzato, un gruppo di giovani intellettuali, anch'essi cattolici, ma liberali moderati, fautori della Costituzione francese del 1814. Due di essi, Santorre di Santarosa e Cesare Balbo, svolgeranno un ruolo di fondamentale importanza nella rivoluzione del $1821^{37}$.

Anche in Piemonte le società segrete ebbero un grande sviluppo subito dopo la Restaurazione, trasformandosi da antinapoleoniche, come in origine, in antigovernative e rivoluzionarie. La più diffusa di queste sette, gli Adelfi -in cui forte era l'influenza di Filippo Buonarroti (Saitta, 1950)- si fuse nel 1818 con i Filadelfi e si trasformò nei Sublimi Maestri Perfetti. Gli aderenti dovevano operare politicamente dirigendo altre organizzazioni, già esistenti o di nuova creazione. Gli obiettivi partivano dalla lotta per la Costituzione e l'indipendenza dall'Austria, per passare alla democrazia e alla repubblica e giungere infine al comunismo.

I Sublimi Maestri Perfetti ebbero grande influenza sui Carbonari dell'Italia settentrionale, ma la società segreta che si diffuse rapidamente in Piemonte e Lombardia tra il 1818 e il 1820, superando colà la Carboneria per numero di affiliati, fu la Federazione Italiana, che si poneva come scopo l'indipendenza dall'Austria e la formazione di una monarchia costituzionale nell'Italia del nord. I Federati lombardi, guidati da Federico Confalonieri, erano in maggioranza borghesi e nobili contrari all'Austria. In Piemonte, invece, pur avendo tra i loro aderenti buon numero di borghesi, i Federati raccolsero proseliti soprattutto nell'esercito e nel gruppo liberale aristocratico cattolico-moderato, con alla testa Santorre di Santarosa.

I Federati piemontesi erano tutti costituzionali, ma mentre la maggior parte, borghesi, sottufficiali e ufficiali inferiori, voleva la Costituzione spagnola del 1812, la minoranza, formata specialmente da aristocratici cittadini, voleva quella francese del 1814, mentre Santarosa era per una versione modificata della siciliana del 1812. Questa divisione non nuoceva all'unità del movimento, poiché tutti i federati erano, prima della rivoluzione napoletana e per un certo periodo anche dopo, concordi nell'idea che ogni riforma costituzionale avrebbe dovuto essere ottenuta per via pacifica chiedendola al sovrano ${ }^{38}$.

36. Sul cattolicesimo reazionario nella Restaurazione è ancora fondamentale il volume di Fontana (1968). Da vedere anche (Verucci, 1968: 1-51; Battista, 1976: 223-249).

37. Sulla Restaurazione in Piemonte, e sulla generazione che preparò la rivoluzione del 1821, sono importanti le considerazioni di Romeo (1960; 1963).

38. «La discrepanza di opinioni dei liberali piemontesi sulla costituzione [...] non impedì la loro franca e leale unione nel tentativo che fecero d'illuminare sullo stato delle cose 
È importante notare che tra il movimento patriottico napoletano e quello piemontese esisteva più d'una differenza, e di notevole importanza. Anzitutto, come ho detto prima, a Napoli il re non poteva più contare sull'appoggio della parte migliore e più illuminata dell'aristocrazia né su quello degli intellettuali e degli scienziati, ma poteva solo sperare che «si ripeta il miracolo del 1799 e dal suolo napoletano prorompano a salvarla contadini e lazzari e briganti» (Croce, 1965: 238).

A Torino, invece, la fedeltà e l'affetto per la dinastia erano uniformemente diffusi e radicati in tutta la società, come testimonia la descrizione del ritorno del re dall'esilio in Sardegna rievocata dopo la rivoluzione del 1821 da un osservatore come Santorre Santarosa:

«Non v'è cuore piemontese che non abbia serbato ricordo del 20 maggio 1814: mai Torino non vide spettacolo più commovente - quel popolo che si accalcava attorno al suo re, [... ]! Nobili, borghesi, popolani di città e di campagna, eravamo allora tutti uniti da uno stesso sentimento: partecipavamo le stesse speranze» (Santarosa, 1920a: 78-79).

Il sovrano era veramente amato da tutti, aristocratici, borghesi e popolo minuto, anche se considerato, e giustamente, persona di scarso intelletto (ecco come Massimo D'Azeglio parlava del re «con quella sua faccia -via, diciamolo- un po' di babbeo ma altrettanto di galantuomo»). (D’Azeglio, 1971: 93)

Inoltre a Torino la preferenza dei patrioti aristocratici e moderati per la Costituzione francese del 1814 rispetto a quella di Cadice derivava da una buona conoscenza delle due Carte, e anche di quella inglese, oltre che, secondo alcuni Autori, dall'essere "parecchi nobili [...] ambiziosi di brigare fra i Pari con una carta all'inglese, od al più alla francese» (Manno, 1879: 10) ${ }^{39}$.

il governo. [...] È poi da notare che il voto di una costituzione liberale vi era espresso fortemente: ma senza però che i principii ne fossero enunciati in maniera da ferire alcuna delle opinioni che ci tenevano divisi». (Santarosa, 1920a: 103) La prima edizione dell'opera di Santarosa uscì a Parigi, De la révolution piémontaise, Paris, Les marchands de nouveautés-Imprimerie de Huzard-Courcier, novembre 1821. Ė importante l'edizione parigina dell'anno dopo, De la révolution piémontaise. Troisième édition, revue, corrigée et augmentée de notes et de l'analyse de la constitution sicilienne, Paris, Alexandre Corréard, 1822.

39. «Nei primi incunaboli di quella rivoluzione, i principali indirizzatori voltavansi più amorosamente al lato settentrionale che al meridionale dei Pirenei. Erano persone coltissime, e vedeano l'immane discrepanza fra il potere unico dell'isola di Leon e il temperato equilibrio della carta borbonica. Erano gentiluomini; e loro non isgradiva il trasformarsi in Pari del Regno»(G. Manno, 1866: 282). 
Il miglior conoscitore della Costituzione spagnola era senza dubbio Cesare $\mathrm{Balbo}^{40}$, che aveva trascorso più di due anni in Spagna, al seguito del padre Prospero, quando questi nell'autunno del 1816 era stato nominato ambasciatore a Madrid. Nella capitale Cesare apprezzò le opere di Jovellanos, fece amicizia con l'ambasciatore inglese Henry Wellesley, con lo studioso americano George Ticknor, con alcuni giovani liberales moderati e approfittò dell'occasione per studiare a fondo sia le vicende della Guerra dell'Indipendenza, di cui iniziò a scrivere una voluminosa storia ${ }^{41}$, sia gli avvenimenti più propriamente militari e gli insegnamenti che se ne potevano trarre ${ }^{42}$, sia, infine, la Costituzione del 1812. La conclusione cui giunse era che non la Costituzione di Cadice, né la francese del 1814, ma quella inglese era la Carta migliore e più adeguata al suo modo di concepire la storia e la politica. Di questa convinzione egli si fece, appena tornato a Torino, appassionato fautore tra i suoi amici, insistendo soprattutto su quelli che per lui erano i difetti fondamentali della Carta spagnola, come risulta chiaro da queste citazioni:

«Ma insomma, giudicando [...] l'opera [cioè la costituzione del 1812] mi pareva non più che una imitazione della costituzione francese del 1791; [...]; tanto più cattiva, che all'errore di porre una sola camera, [...], s'era aggiunto quello di porre una commissione permanente delle corti tra le sessioni, e così di dar tutto alla potenza legislativa, e distruggere la esecutiva; l'errore, in somma, di porre invece d'un governo equilibrato delle tre potenze, uno assoluto di una sola» (Balbo, 1856: 368) ${ }^{43}$.

40. Per lo studio del pensiero e dell'opera di Cesare Balbo -oltre al sempre utile volume di Passerin (1940) - non si può ormai prescindere dai due fondamentali studi che gli ha dedicato Scaglia (1975; 1989). Sempre utile è l'Introduzione premessa da Fubini (1980).

41. Cesare Balbo, Storia della guerra di Spagna e di Portogallo contro Napoleone, Archivio di Stato di Torino (AST), Fondo Balbo di Vinadio (FBV), mazzo (m.) 37, volume (vol.) 5 dei manoscritti (mss.) in folio. È un manoscritto di 606 pagine. Nel volume 6 dei mss. in folio (m 37), c'è un volume di 349 pagine con il titolo generico di Guerra di Spagna e d'America. Abbozzi originali. Tutti e due i testi sono inediti.

42. Tra il 1817 e il 1818 Balbo scrisse gli Studii sulla guerra d'Indipendenza di Spagna e Portogallo scritti da un uffiziale italiano, ma il libro venne pubblicato anonimo solo nel 1847 (Torino, Stamperia Sociale degli Artisti Tipografi), mentre l'anno seguente uscì per i tipi dell'editore Pomba e il nome dell'Autore. Gli Studii e altri inediti di argomento militare sono stati poi pubblicati in Balbo (1935). Alcuni scritti inediti, particolarmente importanti per i riferimenti alla guerriglia, si trovano in Scotti Douglas (2013).

43. Come ho spiegato in modo particolareggiato nella nota 2 del saggio citato nella nota precedente (113-114), Ricotti chiamò Autobiografia di Cesare Balbo un testo che nell'indice manoscritto del volume è chiamato Biografia fatta dall'Autore e che Balbo chiama semplicemente Biografia. Allo stesso modo Ricotti chiamò Vita di Cesare Balbo scritta da lui medesimo (Appendice seconda: 380-386) il testo -anch'esso presente nello stesso mazzo archivistico 42, ms. in folio n. 23 (207-218)- che l'inventario del Fondo chiama Autobiografia di Cesare Balbo. Tuttavia l'uso è ormai quello di citare questi testi coi titoli dati dal Ricotti, quindi li impiegherò anch'io. 
«Perciocché $[\ldots]$, occupatisi $[\ldots]$ i pochi Spagnuoli indipendenti $[\ldots]$, in ideare e discutere e costituire la libertà, $[\ldots]$ non la seppero costituire; e n'uscì quella Costituzione di Cadice, [...] non imitazione nemmeno da niuna buona straniera, [...], ma dalla francese del 1791, con una sola assemblea, ed anzi peggio, con una commissione straordinaria governativa; una impossibilità, una esagerazione parlamentare, una ragazzata liberale, una scioccheria politica» (Balbo, 1859 [1846]: 369).

Con questi argomenti Balbo riuscì a convincere i suoi amici, e anche, almeno da un punto di vista teorico, Santorre di Santarosa. Egli infatti riteneva che Santarosa fosse

«... un cuore, un animo veramente puro [...]; e una mente alta [...], ed anche cólta, ma a cui mancava appunto la sperienza o almeno la coltura politica, [...] ed a cui mancava la cognizione della storia della costituzione [...]. Io aveva preso alquanto di tal cognizione dagli Inglesi e da un Americano con cui avevo vivuto a Madrid, [...] e mi sforzavo di trar l'amico nelle mie opinioni; e in parte vi riuscivo: ed egli disapprovava meco e la costituzione spagnuola e più le rivoluzioni militari; ma ricadeva a conchiudere che ogni sacrificio di opinioni doveva farsi alla patria, all'Italia...» (Balbo, 1856: 373).

In realtà Santarosa non era così sprovveduto e disinformato come Balbo lo dipinge: la sua opinione circa la Costituzione più desiderabile per gli Italiani, e in particolare per i Napoletani, in quel determinato momento storico, ci mostra un intuito finissimo di uomo politico e rivela una conoscenza non superficiale della situazione italiana e internazionale. Vediamola:

«Ma i Napoletani avevan pur essi un antecedente che era forse da non trascurare: la costituzione di Sicilia. Questa [...] non è altro che la costituzione inglese scritta; ma [...] senza l'ineguaglianza nel diritto elettorale e senza quegli avanzi di feudalismo, [...]. Essa era più popolare della Carta francese [...]. Sarebbe stato facile purgarla da qualche difetto [...]. Adottandola, Napoli avrebbe conseguito il precipuo vantaggio di evitare le sanguinose gare colla Sicilia [...]. Avrebbe [...] acquistato una ragione di più per sperare sull'appoggio d'Inghilterra e di Francia. Era questo un vantaggio di tanto momento nella situazione dei Napoletani che si è stupiti come vi abbiano così di leggieri rinunciato» (Santarosa, 1920a: 101-102).

Mi par chiaro, dunque, che Santarosa non era certo il semplice soldato, arricchito da qualche lettura mal digerita, come invece egli stesso vuol far talvolta credere, con un misto di modestia e di civetteria ${ }^{44}$, e come erroneamente ce lo

44. «Io non sono un uomo letterato. Sono un soldato che a niuna setta appartenendo, solo conosce i suoi altari, la sua patria e la sua spada» (Santarosa, 1920b: 3). 
dipinge Victor Cousin nei suoi Ricordi ${ }^{45}$. E il suo comportamento durante la crisi rivoluzionaria del 1821 ne sarà sufficiente controprova.

Anche Maria Teresa d'Austria, moglie di Vittorio Emanuele I, era buona conoscitrice della Costituzione di Spagna, tanto che il 22 aprile 1820 ne raccomandava la lettura al genero Francesco IV di Modena con queste parole: «Vi raccomando la lettura della Costituzione di Spagna, perché la credo necessaria ad un Sovrano» ${ }^{46}$, e di nuovo, scrivendo allo stesso il 21 ottobre, insisteva:

«Ditemi se volete la Costituzione di Spagna, perché credo indispensabile per voi $[\ldots]$ che la leggiate [...] io la lessi 3 volte, e vi posso assicurare che, se non è certamente cattiva quella di Sicilia fatta in Palermo nel 1812, è tantoppiù indegna questa ${ }^{47}$.

La regina era, in effetti, molto aggiornata sulla letteratura politico-giuridica del tempo, e anche dotata di acume, freddezza di ragionamento e presenza di spirito, come vedremo più avanti.

È quindi evidente come la situazione in Piemonte agli inizi del 1820 fosse profondamente diversa da quella di Napoli; il Paese era sì percorso dalla richiesta di mutamento e di riforme, ma questo si univa al desiderio di un allargamento del regno a spese dell'Austria -contro la quale, e non senza incoraggiamento dallo stesso re, si parlava liberamente a Corte- non disgiunto da quello dell'indipendenza d'Italia ${ }^{48}$. Ma non vi era quell'agitazione diffusa e irrequieta, sfociante spesso in scontri armati tra opposte fazioni, che faceva parte normale della vita delle province napoletane.

\section{Linsurrezione spagnola del 1820 e la rivoluzione a Napoli}

Cominciava l'anno 1820 e nella situazione descritta giunsero in Italia le notizie dell'avvenuto pronunciamiento di Riego e Quiroga e, più tardi, del fulmineo e riuscito diffondersi del moto per la Costituzione e, agli inizi di marzo, della sottomissione alla stessa da parte di Ferdinando VII.

In tutto il regno delle Due Sicilie i Carbonari stavano fittamente lavorando a preparare l'insurrezione. Dopo varie riunioni e accordi si era deciso che il moto iniziasse a Napoli nella notte tra il 29 e il 30 maggio, ma per delazioni, arresti e altri problemi di comunicazione fra i diversi centri cospirativi l'impresa

45. Sono premessi da Luzio all'edizione da lui curata de La Rivoluzione Piemontese nel $1821 \ldots$, di Santarosa (1920a: 3-70, specialmente 16).

46. Archivio di Stato di Modena, Archivio Austro-Estense, parte V, Filza X.

47. Ibidem.

48. Una felice analisi dell'influenza dalla Carta gaditana sulla rivoluzione piemontese, con l'impiego di materiale dell'Archivo Histórico Nacional di Madrid, è quella di Butrón (2004). LAutore è poi ritornato sull'argomento in altre occasioni (Butrón, 2011; 2012). 
fu rimandata al 10 giugno, ma neppure per quella data si riuscì a dare inizio al moto. Si tennero ad Avellino due riunioni degli emissari carbonari il 22 e il 24 giugno e da esse uscì la data del 4 luglio. Gugliemo Pepe intanto aveva progettato un'autonoma iniziativa da iniziare il 24 giugno (Pepe, 1847, I: 374-382), ma nemmeno questa andò a buon fine. Fu così che la rivoluzione cominciò a Nola. Qui operava instancabile il prete settario Luigi Minichini (Manfredi, 1932), che aveva reclutato due ufficiali di cavalleria, il tenente Michele Morelli e il sottotenente Giuseppe Silvati. Morelli e Minichini decisero di agire da soli. Nella notte tra il 1 e il 2 luglio si mossero in circa 150, avendo alla testa l'abate Minichini, su un cavallo bianco, abito talare, occhiali e armato di schioppo e gridando "Viva paesani, allegri, viva la libertà e la costituzione» ${ }^{49}$, a suon di tromba marciarono verso Avellino, aggiungendo al loro gruppo altri contadini e soldati. Il 3 entrarono in Avellino tra l'entusiasmo della popolazione, e qui Morelli forzò abilmente il comandante della piazza tenente-colonnello De Concilj a prendere posizione cedendogli il comando degli insorti. Intanto Capua e la sua guarnigione aderivano al moto, garantendo così un'eventuale forte base su cui ritirarsi. Per opera di Guglielmo Pepe e di Antonio Napoletani la notte tra il 5 e il 6 insorgevano a Napoli i reggimenti di cavalleria Regina e Dragoni, e quello di fanteria Real Napoli, che sotto il loro comando uscirono dalla città e raggiunsero Avellino, ove Pepe il 6 luglio assunse il comando di tutti i costituzionali. Quello stesso giorno il re, alle strette e anche su consiglio dei ministri, promulgò questo editto: «Essendosi manifestato il voto generale della Nazione del Regno delle Due Sicilie di volere un Governo costituzionale, di piena nostra volontà vi consentiamo e promettiamo nel corso di otto giorni di pubblicarne le basi» (Alberti, 1926-1931, I: 3-4).

Al medesimo tempo Ferdinando I pubblicò un altro decreto con cui, «dicendo che le sue infermità non gli permettevano di sostenere le fatiche indispensabili a chi governa» (Pepe, 1847, I: 393) nominava il figlio Francesco, duca di Calabria e principe ereditario, suo Vicario con l'alter ego. La promessa parve troppo vaga agli insorti; così si pretese, e si ottenne, che il re in persona, oltre al Vicario, firmasse un altro decreto:

«La Costituzione del Regno delle Due Sicilie sarà la stessa adottata per lo Regno delle Spagne nell'anno 1812 [...]salvo le modificazioni che la Rappresentanza nazionale costituzionalmente convocata crederà di proporci per adattarla alle circostanze particolari de' reali dominj» (Alberti, 1926-1931, I: 12-13).

49. Archivio di Stato di Napoli, Processo di Monteforte, Dichiarazione del 3 luglio 1820 di Cristofaro Balsamo di Nola, incarto 22, 31r.-36v. 
Il 9 luglio si ebbe il trionfale ingresso a Napoli delle truppe costituzionali, con a capo Pepe, Napoletani e De Concilj. Il Vicario e gli altri principi, con tanto di coccarda carbonara, assistettero alla sfilata dai balconi della Reggia. Il re si fingeva malato e aveva già iniziato a tessere la trama del doppio gioco che lo avrebbe portato a rinnegare il giuramento prestato ${ }^{50}$ ma ricevette Pepe e gli altri dirigenti dell'insurrezione. Il Vicario aveva anche provveduto alla nomina di un nuovo governo, tutto di elementi murattiani, e di una Giunta provvisoria di governo -anch'essa a prevalenza murattiana- che sostituisse il Parlamento, fino alla sua convocazione. Si nominò una commissione che traducesse la Costituzione di Cadice, e il 13 luglio il re giurò solennemente «nel nome di Dio e sopra i santi Vangeli» di osservarla, difenderla e conservarla (Alberti, 1926-1931, V: 24).

In pochissimi giorni, e -contrariamente alle tremende previsioni di Metternich: «Le sang coulera par torrents» (Metternich, 1880-1884, III: 360)senza spargimento di sangue, la rivoluzione costituzionale aveva così vinto la sua battaglia, mostrando, da un lato, l'estrema e intrinseca debolezza del regime abbattuto, ma anche, dall'altro, la capillarità della diffusione del desiderio di cambiamento. Il largo sostegno di massa alla rivoluzione dimostra che non si trattò solamente di un semplice pronunciamiento militare, ma di un «movimento assai complesso, che, a differenza della rivoluzione del 1799 , partì dalla provincia» (Maturi, 1969, I: 74-75) ${ }^{51}$.

Esemplare ed icastica è la descrizione che in poche righe Gabriele Pepe fa del successo della rivoluzione:

«In soli quattro giorni senza stille di sangue, senza minima irriverenza alle leggi e all'Autorità, senza neppure intermittenza nel moto della macchina sociale, avviene il rapido, inatteso, incruento passaggio dal Governo illimitato al moderato, fra gioie, benedizioni ed esultanze» (Pepe, 1978, I: 45).

Su questa diagnosi erano d'accordo anche i diplomatici delle potenze della Santa Alleanza di stanza a Napoli come l'incaricato d'affari austriaco (Alberti, 1926-1931, V: 40), e l'ambasciatore britannico A'Court ${ }^{52}$.

Il fatto che la rivoluzione avesse avuto una nascita provinciale spiega la decisa scelta in favore della Costituzione spagnola, anche se non ben conosciuta. Infatti la Carta spagnola limitava fortemente i privilegi dei nobili e il potere regio, fornendo così una certa garanzia di uguaglianza politica alla

50. Si vedano ad esempio le lettere del re ad Alvaro Ruffo a Vienna del 16 e 22 settembre 1820 (Alberti, 1926-1931, V: 321-326, 330-331).

51. Anche Candeloro (1956-1986, II: 79-85). Sull'origine provinciale della rivoluzione si veda Lepre (1967).

52. Lettera al ministro Castlereagh del 24 agosto 1820 (Alberti, 1926-1931, V: 34-35). 
borghesia sia cittadina che provinciale, la quale sperava anche, tramite la Costituzione, di frenare l'egemonia prepotente di Napoli. Vi fu infatti, almeno all'inizio, una qualche inclinazione al federalismo regionale, e anche questo favoriva la preferenza per la Carta spagnola, che tale forma di confederazione tra province prevedeva.

Purtroppo la Costituzione del 1812 introdusse un grave elemento di discordia tra i Carbonari che avevano fatto e vinto la rivoluzione - «un esercito senza generali propri»-, e quelli a cui era stata ceduta la direzione del moto, ossia i murattiani «un magnifico Stato maggiore di tecnici senza soldati». Costoro, «...sostenitori del dispotismo illuminato, $[\ldots]$ solo tenendo conto di particolari circostanze, estere ed interne, si sarebbero spinti fino alla costituzione di Francia del 1814, [...] la costituzione di Spagna del 1812 era per loro una costituzione troppo 'anarchica'»(Maturi, 1969, I: 75).

I Carbonari non erano in grado di gestire il successo rivoluzionario, e quello che chiedevano era in pratica una tutela giuridica nei confronti del potere regio, insieme a una buona dose di gretto conservatorismo sociale, giacché la borghesia provinciale cui quasi tutti appartenevano era nata dal lento sgretolarsi della società feudale, non dalla trasformazione capitalistica dell'agricoltura, né dalla creazione di nuove attività imprenditoriali di tipo industriale. Era un personale politico pieno di entusiasmo idealistico, ma generalmente rozzo e ignorante, ben esemplificato dalla persona del prete Minichini, del quale «...si narra che, nella prima giornata del Consiglio di sicurezza, chiese al presidente se avesse un esemplare della Costituzione di Spagna. Ho fatto tanto, disse egli, per questa costituzione e non per anco l'ho letta» (Manfredi, 1932: 90).

Come lucidamente vide Benedetto Croce i murattiani -cioè coloro che effettivamente gestirono e diressero il Paese negli otto mesi del periodo costituzionale- erano vecchi, anche se tra chi fece la rivoluzione molti erano i giovani (Croce, 1965: 250-251).

Uno dei primi decreti del nuovo governo fu quello del 26 luglio che sanciva all'articolo 1 l'abolizione dei regi revisori «della stampa, quanto de' libri esteri che s'immettono e circolano nel Regno delle due Sicilie», e all' articolo 2: «Ogni individuo è libero di scrivere, stampare e pubblicare le sue idee: l'autore non però, o lo stampatore, se l'autore fosse anonimo, sarà sempre responsabile al Governo, e sottoposto alle pene espresse nei seguenti articoli» (Alberti, 19261931, I: 90).

Si dava così sanzione legale all'incredibile numero di pubblicazioni di ogni tipo -periodiche od occasionali- che avevano visto la luce nei giorni immediatamente successivi al trionfo della rivoluzione. Prima del luglio ad esempio si 
pubblicava soltanto l'organo ufficiale del Governo, Il Giornale del Regno delle due Sicilie, e qualche mensile di varietà, mentre nei nove mesi costituzionali videro invece la luce ben trentatré tra giornali, gazzette e riviste, di tendenza e periodicità disparate $e^{53}$. In questo grande fervore editoriale è interessante verificare come l'argomento della Costituzione, la sua spiegazione e diffusione tra i cittadini, e le modifiche da apportare a quella spagnola venissero ai primi posti.

Un posto a sé tengono i vari Catechismi, agili opuscoli in forma di domanda e risposta, come il catechismo cattolico. Ne abbiamo di due tipi: nel primo caso si tratta del Catechismo costituzionale della monarchia spagnuola... Prima traduzione italiana, versione di un'analoga pubblicazione spagnola, nel secondo troviamo anzitutto l'opuscolo anonimo Catechismo per la nazione del Regno delle due Sicilie, pubblicato dalla tipografia A. Nobile, poi il Catechismo costituzionale per uso del regno unito delle Sicilie, di Luigi Galanti, che ebbe addirittura tre edizioni nel corso del secondo semestre $1820^{54}$. Infine l'anonimo e interessante Catechismo istituzionale Per uso del regno unito delle Sicilie, pubblicato da Francesco Del Vecchio. La prefazione è datata 18 luglio 1820, e l'Autore vi dice di aver lavorato febbrilmente per poter in pochi giorni fornire ai cittadini un'idea di cosa fosse la Costituzione. È infatti una spiegazione semplice e chiara della Carta spagnola, con proposte di modifiche e miglioramenti da apportarvi per Napoli.

A riprova di quanto generalizzato fosse l'interesse per gli argomenti costituzionali, da un lato, e dell'intensità dello sforzo fatto per renderli chiari e accessibili a tutti gli strati della popolazione, dall'altro, troviamo anche delle pubblicazioni in dialetto, come la Chiacchiariata che se fanno pe tre matine lu Cuorpo de Napole e lu Sebeto a S.Lucia ncoppa a la Custetusione di Salvatore Grasso e, sempre dello stesso Autore, il corso in tre lezioni La scola custetuzionale pe li piccirilli, edito dalla Stamperia Garruccio.

Sono anche da citare le pubblicazioni encomiastiche e celebrative, in versi o in prosa, di taglio laico o religioso, come il Piccolo Parnaso costituzionale, o sia

53. Per un sommario esame dei principali giornali del periodo costituzionale Alberti (19261931, I: XXXII-XXXVI). Uno studio più approfondito della stampa napoletana del periodo si trova in Rocco (1921: 35-47); e soprattutto in Taliento (1920). Lanalisi più recente, anche se forzatamente non troppo particolareggiata, si può vedere in Galante Garrone; Della Peruta (eds.) (1979). Il saggio in questione è di Galante Garrone, I giornali della Restaurazione 1815-1847: 3-246, per Napoli, 81-97. Corciulo (1991) si è spesso occupata dell'argomento e il suo più recente volume (2010) dove tra l'altro riprende e aggiorna un suo vecchio studio pubblicato nel 1984 (Nuovi studi politici, 4) su La Minerva napolitana ed i moti del 1820-21.

54. Le prima edizione, di 60 pagine, venne pubblicata da Francesco Del Vecchio, la seconda, identica, da Domenico Sangiacomo, la terza, di 88 pagine, dal Gabinetto Letterario. Tutte a Napoli. 
Saggio poetico della classe rettorica del collegio del signor Pietro Merlin nell'esame dell'anno 1820, edito dalla Tipografia Francese, o L'opera di Dio nel governo costituzionale monarchico proclamato in Napoli a' 9 luglio 1820, di Giuseppe Polifroni, pubblicata da Chianese.

L'ondata pubblicistica continuò nei primi mesi del 1821, ma per l'argomento che ci interessa vogliamo ricordare soltanto tre opere. La prima è la versione adattata alle Due Sicilie della Carta gaditana, in almeno due edizioni, una per i tipi di Raffaele Di Napoli, Costituzione politica del Regno delle Due Sicilie, e l'altra, ufficiale, Costituzione politica del Regno delle Due Sicilie Edizione fatta per ordine e sotto la direzione del parlamento, Dalla stamperia del parlamento nazionale. La seconda è la traduzione, puntualissima e celere trattandosi di un volume uscito in Francia solo l'anno prima, della trattazione di Jean-Denis Lanjuinais, Considerazioni politiche su i cambiamenti da farsi alla Costituzione di Spagna per assodarla specialmente nel regno delle due Sicilie. Opera... recata in italiano dal sig. Filippo Marzullo, edita dal Gabinetto Letterario ${ }^{55}$. Le Considerazioni suscitarono molto interesse e un vivace e anche polemico dibattito, testimoniato ad esempio dagli articoli dedicati al volume da La Minerva Napolitana nel gennaio $1821^{56}$. A proposito della Minerva, credo valga la pena ricordare che questo bel settimanale fu in assoluto il primo in Italia a pubblicare uno scritto dal significativo titolo Della guerra di parteggiani teorizzante la guerra di guerriglia, il cui autore viene indicato come «un uffiziale che si è distinto nelle guerre di Spagna» ${ }^{57}$. Il terzo volume che vogliamo citare è La Costituzione Spagnuola esaminata secondo i principj della ragione, e modificata secondo le circostanze del regno delle due Sicilie. Ne era autore Carlo Mele ed editore Giovanni de Bonis. Ebbe una breve ma lusinghiera recensione sulla Minerva agli inizi del $1821^{58}$.

La Costituzione adattata merita qualche parola. Erano 371 articoli divisi in dieci titoli, e gli articoli più interessanti -a mio parere- erano senza dubbio il terzo, il quarto, il dodicesimo, il quindicesimo, il sedicesimo -col suo corollario

55. Il titolo originale era: Vues politiques sur les changemens à faire à la Constitution de l'Espagne, à fin de la consolider, spécialement dans le Royaume des Deux Siciles, Paris, Baudouin, 1820.

56. La Minerva Napolitana diede prima l'annuncio della comparsa dell'opera nell'edizione originale nel fascicolo 16 (dicembre 1820,309, nota 1), e iniziò a discuterla nel fascicolo 17 (341-350), per continuare poi nel fascicolo 19 del 10 febbraio 1821, 1-15. Vi fu anche, sull'argomento, una lunga lettera da Parigi, datata 31 gennaio 1821, di Luigi Angeloni -già tribuno della Repubblica Romana del 1792 e direttore della Minerva-, pubblicata nel fascicolo 20, 71-85, e 21, 110-125.

57. La Minerva Napolitana, fascicolo 20: 59-70, e 21: 126-152. Il testo è stato ripubblicato in tempi recenti (Liberti, 1972: 373-385).

58. La Minerva Napolitana, fascicolo 17: 416-417. 
articolo 163-, e infine l'articolo 165 col lungo elenco delle dodici restrizioni dell'autorità regia.

È molto evidente, letti questi articoli, la ragione per cui questa Costituzione facesse paura non solo a tutte le Cancellerie europee, ma anche a quei novatori prudenti, e che oggi definiremmo di destra moderata, all'interno stesso dei governi rivoluzionari, a Napoli come a Madrid. Sarà proprio questa paura, e la conseguente inerzia nell'azione statale e diplomatica in difesa della Costituzione, una delle cause principali del rapidissimo disgregarsi -persino incredibile se consideriamo l'ampiezza che aveva avuto il successo del moto rivoluzionario- della volontà di resistenza delle popolazioni meridionali, e il rifiuto della scelta di portare la rivoluzione oltre i confini del Regno, coinvolgendo così gli abitanti degli Stati vaticani e tentando di iniziare un più generale moto di riscatto italiano. Questo era in effetti ciò che si aspettavano i liberali piemontesi e, anche, ciò che temeva la diplomazia pontificia, da un lato, e Metternich e i governi di Vienna e Pietroburgo, dall'altro.

Il Parlamento napoletano, composto prevalentemente da moderati, non rispecchiava gli umori della piazza né quelli estremisti dei Carbonari e avrebbe voluto giungere a un compromesso con le potenze radunate a Troppau per evitare l'intervento austriaco, passando dalla Costituzione spagnola a quella francese, e pare in effetti che un simile tentativo venisse fatto da re Ferdinando su iniziativa dei ministri Zurlo e Carrascosa, «[...] les deux hommes les plus capables du nouveau régime, l'un et l'autre convaincu depuis longtemps que la Constitution d'Espagne ne pouvait et ne devait pas subsister à Naples» (Gentz, 1877, II: 105) $)^{59}$.

Tuttavia, quando il re lesse il progetto di Costituzione agli ambasciatori riuniti, essi tacquero perché le istruzioni dei rispettivi governi vietavano loro di consentire a un simile progetto, pur se non potevano impedire al re e ai suoi ministri moderati di tentare ogni mezzo per avere dal Parlamento il permesso perché Ferdinando potesse recarsi a Lubiana. Ma il Parlamento, che avrebbe volentieri accettato la proposta, per timore delle violenze dei Carbonari pretese l'impegno della difesa della Costituzione spagnola, e questo -con grande sollievo dell'Austria (e anche del Piemonte)- risolse ogni problema. Ci dice infatti il segretario del congresso di Lubiana:

«Dès que le Parlement a annoncé qu'il ne voulait que la Constitution d'Espagne, il a mis tous les avantages du coté des Puissances. Le terrain est éclairci

59. Quest'opera, insieme alle memorie del barone Pasquier, all'epoca ministro francese degli Esteri (Pasquier, 1894), e naturalmente a quelle già citate di Metternich, costituiscono la fonte fondamentale per vedere da dietro le quinte come le grandi potenze decidessero l'intervento a Napoli. 
et nettoyé. Les Cabinets d'Autriche, de Russie et de Prusse sont fermement décidés à ne jamais reconnaître pour Naples la Constitution d'Espagne» (Gentz, 1877, II: 110).

Comunque Ferdinando, anche se avesse promesso un'altra Costituzione, se la sarebbe certamente rimangiata, senza contare che le potenze europee non glielo avrebbero in nessun caso consentito. Metternich fu esplicito: rispondendo al ministro russo Capodistria che, alludendo a un regime rappresentativo, gli chiedeva: «Et si le Roi de Naples voulait adopter lui-même un pareil ordre de choses? , rispose seccamente: «L'Empereur ferait la guerre au Roi de Naples» ${ }^{60}$.

È noto come agli inizi del marzo 1821 le baionette austriache avessero facilmente ragione ad Antrodoco del disunito e disanimato esercito costituzionale napoletano -privo per di più delle truppe migliori e meglio armate, oltre dodicimila uomini, alle prese con la ribellione siciliana- e come il re spergiuro potesse così tornare sul trono da padrone assoluto, ribadendo da un lato la definitiva frattura con la classe colta, e dall'altro il legame con la plebaglia più retriva.

Aveva così termine quello che il marchese Orazio De Attellis ${ }^{61}$ avrebbe chiamato, in un suo scritto pubblicato quello stesso anno nell'esilio di Barcellona, L'Ottimestre costituzionale delle Due Sicilie, autenticamente documentato, da servire alla storia di quel regno ${ }^{62}$. A epigrafe di questo glorioso e infelice periodo ecco un brano dell'intervento di Luigi Dragonetti nel corso dell'ultima seduta del Parlamento, tenutasi il 21 marzo 1821, solo due giorni prima dell'entrata degli austriaci. In appoggio alla nobile mozione di protesta di Giuseppe Poerio -poi votata all'unanimità dai 46 deputati presenti- egli disse:

«Noi non siamo qui adunati pel solo interesse degli attuali viventi, ma lo siamo ancora per quello delle future generazioni, che giudicheranno la nostra condotta. Esse certamente non hanno demeritato che noi sacrificassimo pure la nostra vita, quando non fosse che per tramandargli una memoria onorata, per cui conoscano che, se a' nostri giorni periva la gloria militare de' Napolitani, la civile si serbava incontaminata e risplendeva anche in mezzo alle più terribili fasi dell'infortunio» (Alberti, 1926-1931, III: 642).

60. Dal rapporto n. 4 da Lubiana, datato 15 e 16 febbraio 1821, del marchese di San Marzano a Vittorio Emanuele I, pubblicato in (Avetta, 1924, I: 218).

61. Nato a Campobasso nel 1774, abbracciò gli ideali della Rivoluzione francese, combatté per la Cisalpina e l'Impero in Spagna e in Russia. Esule in Spagna dopo il fallimento della rivoluzione napoletana, si batté nelle file dei costituzionali. Fu poi in Messico e lottò per l'indipendenza di quel paese. Tornò in Italia nel 1848 e partecipò alla Repubblica Romana. Morì a Civitavecchia nel 1850.

62. Ne esiste copia manoscritta nella Biblioteca Nazionale di Napoli, ms. V-A-4748. 


\section{La rivoluzione a Torino}

In Piemonte la rivoluzione di Napoli era stata accolta con entusiasmo dai liberali e grande preoccupazione dalla Corte e dall'opinione conservatrice -che già aveva visto di malocchio, nel settembre del 1819, la nomina a ministro degli Interni del riformatore moderato Prospero Balbo- poiché già il 20 luglio Sylvain Costa de Beauregard, scudiero di Carlo Alberto, così scriveva nel suo diario: «Siamo sull'orlo del precipizio... Innumerevoli affissi dimandano la costituzione delle Cortes spagnuole. Il Re è subissato da memorie anonime che lo consigliano a dare la costituzione per far dispetto all'Austria. [...] Si trovavano proclami incendiari fin nell'oratorio della Regina» (Costa, 1889: 100 e 106).

A Torino durante i pubblici festeggiamenti per le nozze di Maria Teresa di Savoia col principe di Lucca Carlo Lodovico di Borbone si trovarono affissi manifesti con la scritta "Costituzione o morte» ${ }^{63}$. In un messaggio al cardinal Consalvi del 24 luglio l'abate Romualdo Valenti, incaricato d'affari pontificio a Torino, scrive: «Si diceva questa mane a Corte, che si fossero trovati affissi agli angoli della città i più frequentati, alcuni biglietti manoscritti, coi quali si domandava la Costituzione. Ma niuno ne fa caso, riguardando la cosa come parto effimero di qualche testa riscaldata ${ }^{64}$.

Lunico uomo di governo che vide lucidamente i pericoli che si andavano addensando sul regno, sia per la generale condizione di agitazione degli animi, sia soprattutto grazie al successo dei costituzionali napoletani, fu Prospero Balbo $^{65}$, che fin da luglio ${ }^{66}$-dopo aver messo in guardia il re e il governo sui pericoli che si correvano- iniziò da un lato la febbrile redazione di abbozzi di leggi costituzionali che avrebbero dovuto condurre alla stesura di una Costituzione

63. AST, Processi politici del 1821, m. 14, 2, deposizione Filippone e Craveri.

64. Archivio segreto Vaticano (AsV), B. 256-260, Romualdo Valenti al card. Consalvi, Torino 24 luglio 1820.

65. Per comprendere l'importanza dell'opera d'intellettuale e di statista riformatore di Prospero Balbo è fondamentale la corposa biografia in due volumi che gli ha dedicato Romagnani (1988-1990). Sempre necessaria, poi, per la migliore comprensione degli avvenimenti del marzo 1821 e del periodo immediatamente precedente è la lettura del saggio di Passamonti (1927), che si avvale anche di documenti ormai purtroppo scomparsi.

66. «Non bisogna più oltre dissimularci l'uno all'altro di noi, ciò che purtroppo a tutti è manifesto, l'evidenza d'imminente gravissimo pericolo. Un morbo contagioso e letale ha più o meno assalito i corpi tutti politici», Annesso al Consiglio di Conferenza 18 luglio 1820, in Lemmi (1926: 36). 
per il regno sabaudo ${ }^{67}$, dall'altro un'opera tenace e discreta di persuasione del sovrano, in buona parte neutralizzata dai messaggi che il ministro San Marzano mandava da Lubiana, oltre che dall'ostinata cocciutaggine di Vittorio Emanuele I, saldamente ancorato al principio dell'assolutismo. Prospero avrebbe preferito la costituzione inglese, ma per non dare adito all'accusa di esterofilia riteneva un buona soluzione per il Piemonte una Carta simile a quella siciliana, ma adattata al Piemonte, utilizzando così un testo nato in Italia.

Così lo statista giustificò nel suo diario la scelta della carta siciliana: «Costretto alla scelta, sarei stato per la Siciliana, conforme alla Inglese, ma scritta ed Italiana, e già guarentita dall'Inghilterra alla Sicilia, come anche di recente ne aveva fatto cenno il Ministero Inglese nelle ultime discussioni del Parlamento ${ }^{68}$.

Intanto i progetti cospirativi prendevano vigore, soprattutto ad Alessandria, città importantissima perché era il maggior centro militare del Piemonte. Qui l'influenza dei Federati era fortissima sia tra i civili che tra i militari, e la tendenza dei patrioti era più decisamente democratica e quindi favorevole alla Costituzione spagnola. A Torino, intanto, erano attivissimi nell'opera di propaganda delle rispettive Costituzioni l'ambasciatore francese, duca Dalberg, e lo spagnolo, Eusebio de Bardaxi, secondati da tutto il corpo diplomatico, giacché anche l'ambasciatore di Baviera, conte di Sciboltdors, faceva propaganda liberale nei salotti torinesi, e persino monsignor Valenti «non contento di farsi vedere nella più cordiale intimità col trio degli ambasciatori liberaleggianti, [...] lasciava capire di non essere poi tanto lontano dalle idee di quei suoi amici e colleghi» (Spini, 1990b: 67) ${ }^{69}$.

Non mi dilungherò sull'attività di propaganda dell'ambasciatore Bardaxi, illustrata a suo tempo da Giorgio Spini (1990b: 65-73) -che rileva come il diplomatico spagnolo fosse così moderato «da considerare con maggior simpatia la istaurazione della costituzione francese» (Spini, 1990b: 72) - né su quella, per contro piuttosto dilettantesca (Torta, 1908: 38 ${ }^{70}$, del suo collega francese; occorre invece sottolineare come la gran massa della popolazione -le «classi

67. «Egli aveva infatti iniziato uno studio analitico delle costituzioni inglese, francese e spagnola, incaricando il figlio Cesare di studiare a sua volta la costituzione siciliana del 1812 confrontandola con la osservazioni critiche svolte su di essa dal giurista francese Jean-Denis Lanjuinais». (Romagnani 1988-1990, II: 492). Si veda anche Pivano (1934).

68. Diario di avvenimenti del Conte P.B., Domenica 11 marzo. Questo Diario, ampiamente citato da Passamonti (1927), è purtroppo scomparso, come altre carte preziose dell'archivio Balbo, fiduciosamente fatto consultare dalla famiglia, quando ancora ne era depositaria, a storici forse non troppo scrupolosi.

69. Per l'atteggiamento del nunzio Valenti, Negri (1927, II: 466-502)

70. Vedi anche Rivista storica del Risorgimento Italiano, I, 1895: 638, e Rinieri (1902: 94-95). 
basse»-fosse perfettamente indifferente a tutta l'agitazione cospirativa, sentita come estranea e non suscettibile di procurarle qualche tangibile e immediato vantaggio, e neppure sapesse pronunciare la parola «Costituzione», che storpiava in dialetto in Costipassion, chiamando così per dileggio Costipati i nobili e i borghesi che tentavano di spiegare che cosa fosse e perché fosse desiderabile questa cosa astrusa e invisibile (Torta, 1908: 59; Ottolenghi, 1881: 91-92). Incomprensione e apatia creavano purtroppo le premesse per quel distacco delle masse popolari dal gruppo dirigente dell'insurrezione che aiutò in modo sensibile l'opera dei fautori del ritorno al precedente governo assolutistico.

Col passar dei mesi e con la decisione austriaca di intervenire a Napoli gli scopi dei liberali piemontesi vennero a definirsi nettamente intorno a due ben precisi obiettivi: l'ottenimento di una Costituzione -che per i motivi già esposti doveva essere quella spagnola-, e la guerra per liberare il Lombardo-Veneto e cacciare l'Austria dall'Italia. Tutti i cospiratori erano uniti nell'intenzione di coinvolgere il sovrano in un progetto che prevedesse sì la Costituzione, ma soprattutto la guerra all'Austria -approfittando del fatto che la spedizione in corso contro Napoli lasciava sguarnite di truppe le province settentrionali-con il conseguente ingrandimento territoriale del regno almeno alla Lombardia se non a tutto il Lombardo-Veneto e il raggiungimento dell'indipendenza italiana sotto lo scettro della dinastia sabauda. Che il momento fosse strategicamente propizio all'invasione della Lombardia è provato sia dalle preoccupazioni espresse dal conte Strassoldo, governatore della Lombardia, quando già il 29 luglio 1820 scriveva a Metternich che «[...] si la peste politique gagnait le Piémont, l'armée piémontaise $[\ldots]$ nous menacerait de trop près pour que nos garnisons actuelles puissent mettre la Lombardie à l'abri de toute chance défavorable ${ }^{71}$, sia dai timori, avuti nei giorni precedenti, confessati a Torino dal generale austriaco Bubna alla contessa di Sambuy dopo il riuscito intervento per schiacciare la rivolta nel marzo 1821 (Torta, 1908: 41). Con il loro progetto i cospiratori confidavano di poter ottenere il consenso del sovrano e di quella parte della nobiltà che, pur conservatrice in politica, era da sempre strettamente votata all'accrescimento delle fortune della dinastia. Ciò vide assai acutamente monsignor Valenti, che il 7 agosto così ne scrisse in un messaggio in cifra al cardinal Consalvi:

«Tra i clandestini indirizzi minacciosi di costituzione e di rivoluzione, che dagli occulti settarii si fanno quà e là da qualche tempo pervenire anonimamente alle mani $[\ldots]$ del Sovrano, uno ve ne ha concepito con le sole tre

71. Wien, Haus-Hof und Staats-Archiv, Berichte des Gsn. Strassoldo Vürs Mailand, (125), Rapporto intorno alle condizioni politiche dell'Austria nelle Lombardia, pubblicato da Alfred Stern in Rivista storica del Risorgimento italiano, I, 1895: 571. 
seguenti parole-Savoja, Italia, Costituzione-il cui senso spiega il voto per un re Costituzionale per tutta l'Italia, e che sia questi della Casa di Savoja, né ne hanno mai fatto un mistero gli stessi rivoluzionarii ne' loro discorsi, ne' loro scritti, e molto meno nelle loro assemblee» ${ }^{72}$.

I rapporti con i patrioti lombardi vennero così infittendosi nell'autunno e inverno del 1820, per concordare una sollevazione che, effettuandosi in Lombardia contemporaneamente a quella piemontese e all'entrata in guerra, avrebbe fortemente ostacolato la reazione militare austriaca e potentemente collaborato allo scopo finale dell'indipendenza dallo straniero. Benché la polizia austriaca fosse riuscita, nell'ottobre 1820, a scoprire a Milano la vendita carbonara di Pietro Maroncelli e lo avesse arrestato insieme a Silvio Pellico e diversi altri complici, i Federati lombardi continuarono a tessere le fila della cospirazione. Nel settembre il conte Perrone si recò in Lombardia con una lettera per il conte Confalonieri del Principe Carlo Alberto di Carignano, cui sarebbe spettato il trono dei Savoia per la mancanza di eredi diretti di re Vittorio Emanuele I e del fratello Carlo Felice, duca del Genevese.

Il Principe si era da tempo mostrato molto vicino agli ambienti liberali, che non facevano mistero della loro intenzione di chiedergli di capeggiare il movimento riformatore. Confalonieri era assente, e il previsto incontro con Perrone avvenne quindi in novembre; in esso il piemontese fornì al nobile lombardo, che più tardi-dopo l'arresto- ripeté fedelmente e per esteso il contenuto dei colloqui alla polizia austriaca, tutto il piano dell'insurrezione, cui secondo Perrone aderivano Carlo Alberto -alla testa dei fautori della Carta francese-, buona parte degli alti ufficiali dell'esercito, quasi tutti gli ufficiali inferiori e metà dei ministri. Il progetto mirava all'instaurazione di un regime costituzionale, preferibilmente di tipo francese e con l'assenso del re. Altrimenti si prevedeva l'abdicazione di re Vittorio a favore del Principe di Carignano (Salata, 1940-1941, I: 90-95, Costituto del 28 marzo 1822; 102-111, Costituto del 29 marzo 1822). In seguito a queste notizie i lombardi mandarono a Torino Giuseppe Pecchio ${ }^{73}$, che garantì la più completa collaborazione della nobiltà lombarda, citando in appoggio i nomi più illustri dell'aristocrazia, talvolta anche esagerando l'ampiezza della cospirazione e la debolezza delle guarnigioni austriache. Come ben scrisse Gualterio a questo proposito:

72. AsV, B. 256-260, Romualdo Valenti al card. Consalvi, Torino 7 agosto 1820.

73. Giuseppe Pecchio era uno dei pochi nobili lombardi che preferiva la Costituzione spagnola: «Inoltre il Pecchio aveva più simpatia per la costituzione spagnola, democratica, che per la francese, aristocratica, vista di buon occhio fra gli italici puri». (PrezzolinI, 1913: 12). Quando fu in esilio Pecchio viaggiò in Spagna e Portogallo, e pubblicò le sue intelligenti osservazioni, prima in Spagna, poi in Inghilterra (Pecchio, 1821; 1822; 1823). Li si veda ora (Pecchio, 1978). 
«I ragguagli delle società segrete di Lombardia, in cui si parlava d'insurrezioni, di generale fermento, $[\ldots]$, non potevano non fare grande impressione sopra fantasie già riscaldate e cuori per natura bollenti! Non si mise più in dubbio né il dovere né la possibilità di una rivoluzione costituzionale; [...] e si decise di prendere quell'occasione per emancipare la Lombardia, facendo guerra all'Austria. Il disprezzo delle forze materiali di essa era [...] soverchio, in coloro che avevano militato coi Francesi,[...]: e questi formavano appunto il nucleo del partito liberale piemontese» (Gualterio, 1861, III: 41).

Ciò non fece che rinfocolare l'entusiasmo dei congiurati piemontesi che persero ogni ritegno nel manifestare, anche pubblicamente, le loro intenzioni. Aiutati dalla «supina indifferenza» delle autorità di polizia e di governo (Sauli, 1908, I: 431-432), di cui sono testimonianza i molti episodi citati da Autori diversi (Sauli, 1908; Gifflenga, 1879: 107-108), oltre che dalle lamentele espresse a posteriori da Carlo Alberto, sia negli scritti apologetici direttamente di suo pugno, come il Rapport et détails de la Révolution qui eut lieu en Piémont dans le mois de mars 1821, steso appena un mese dopo i fatti, e la famosa relazione A.M.D.G., che sta per Ad Maiorem Dei Gloriam ${ }^{74}$, scritta a Racconigi nell'agosto 1839; sia in quelli di Rodolphe De Maistre, ispirati dal principe e stesi utilizzando materiali e documenti da lui forniti, che ebbero larga diffusione ${ }^{75}$. Esemplare al proposito è un brano del messaggio in cifra che monsignor Valenti spedì al cardinal Consalvi in data 11 dicembre:

«Intanto da chi dovrebbe essere allarmato da questi sintomi non prendesi alcuna misura per prevenirne lo scoppio, che anzi [...] si vuole credere che nulla vi sia a temere volendosi avere tutta la confidenza nell'obbedienza delle popolazioni e nella fedeltà della truppa armata... ${ }^{76}$

Che la situazione stesse precipitando verso una soluzione rivoluzionaria dovette constatare con preoccupazione Cesare Balbo, appena tornato a Torino dopo aver trascorso sei mesi a Genova con la sua brigata, mesi trascorsi a elaborare, in settembre, uno studio (perduto con la scomparsa del volume decimo dei manoscritti in $4 .^{\circ}$ ) dal titolo significativo: Esame della Costituzione Spagnuola del 1812, coi cambiamenti proposti da Lanjuinais pel regno delle

74. I due testi si possono trovare in Manno (1879: 58-87, la relazione A.M.D.G. 119-126). Quest'ultima era stata pubblicata per la prima volta da Odorici (1872: 217-224). I documenti sono poi stati ripubblicati, insieme col Simple Récit, in Fiorini (1900). Il Rapport fu anche pubblicato in Degli Alberti (1908).

75. Si tratta del Simple Récit des événements arrivés en Piémont dans le mois de mars et d'avril 1821. Par un officier piémontais, Paris, Chez Méquignon, MDCCCXXII, e di Les trente jours de la Révolution piémontaise, en mars 1821; par un Savoyard spectateur de tous les événements, Lyon, Chez Rusand, 1822, ambedue pubblicati anonimi e violentemente contrastati dagli esuli, soprattutto da Santarosa.

76. AsV, B. 256-260, Romualdo Valenti al card. Consalvi, Torino 11 dicembre 1820. 
Due Sicilie. È di quegli stessi giorni la Professione di fede politica ${ }^{77}$, spedita a Santarosa il 18 ottobre. In essa, oltre a considerazioni sulla necessità di una riforma costituzionale moderata, da compiersi gradualmente, «desiderabile per via del governo, $[\ldots]$ da temersi e fuggirsi per via del popolo ${ }^{78}$, il patrizio piemontese esprimeva diverse valutazioni sull'impossibilità di una rivoluzione popolare e militare. Ma appena rientrato nella capitale il giovane Balbo si rese conto che le sue previsioni pessimiste erano state superate dalla realtà, e vide come una serie di fatti, benché diversi e scollegati, avrebbe avviato la valanga insurrezionale.

Il primo di questi fu il discorso del conte Borgarelli, primo presidente del Senato, ministro degli Interni prima di Prospero Balbo, in occasione dei tradizionali auguri d'inizio d'anno al sovrano. Rivolto al re Borgarelli ammonì: «Sire, degnatevi ricordare che le antiche leggi dello Stato sono le guardiane della sua sicurezza e del suo splendore. Non permettete che mano indiscreta osi toccarle» (Santarosa, 1920a: 90) ${ }^{79}$. Queste parole gelarono l'assemblea, poiché era chiaro come la «mano indiscreta» fosse proprio quella del conte Balbo, da cui tanto si aspettavano i liberali (Santarosa, 1920a: 86-87; Sauli, 1908, I: 432-436), e lo sconforto si diffuse poi per tutta la città quando fu chiaro che il re non aveva alcuna intenzione di chiedere a Borgarelli di dimettersi. Prospero Balbo, invece, rinunciò a farlo dietro le insistenze del re e degli amici più vicini. Così tutta la fazione più retriva e ottusa dell'aristocrazia di corte -quella «demi-douzaine d'imbéciles» come la chiamava lo stesso Balbo $^{80}$ - aveva dimostrato a se stessa e al Paese la sua forza da un lato, e dall'altro la precisa determinazione di non permettere che le cose cambiassero, anche di poco ${ }^{81}$.

Pochi giorni dopo, l'11 e il 12 gennaio, la violenta e sproporzionata reazione della polizia e dell'esercito sugli studenti che reclamavano contro l'arresto di quattro loro compagni, solo colpevoli di aver fatto chiasso in teatro (Egidi,

77. AST, FBV, tomo XXIII dei ms. in folio, 105-108. È stata pubblicata da Ricotti (1856: 393-395).

78. Ibidem, 394.

79. Limportanza del discorso di Borgarelli e l'impressione che suscitò risultano da molte altre fonti, ad esempio Balbo (1926: 211) -il testo originale era nel volume XIII dei ms. in 4..$^{\circ}$ (Ricotti, 1856: 440), purtroppo perduto da tempo-; Sauli (1908, I: 436-438). Un'interessante testimonianza sul discorso di Borgarelli si trova in Gallavresi (1912).

80. Prospero Balbo, Lettera del 28 gennaio 1821 all'amico marchese Filippo Antonio di San Marzano, ministro degli Esteri, AST, Raccolta Balbo, Documenti per la Rivoluzione del 1821.

81. Su tutto l'episodio e in generale sull'azione di Prospero Balbo nel periodo della Restaurazione è sempre utile il saggio di Passamonti (1927, II: 190-348). Si veda ora, per un'analisi più completa e storiograficamente aggiornata Romagnani (1988-1990, II: 371-672). 
1926:109), fu sì un'altra vistosa dimostrazione di forza della parte reazionaria contro la ragionevolezza e l'intelligenza di Prospero Balbo- il consiglio dei ministri del 14 confermò infatti la linea dura adottata e rigettò le proposte di clemenza avanzate da Balbo e Saluzzo ma anche la decisiva scintilla che avrebbe, entro due mesi scarsi, provocato l'insurrezione ${ }^{82}$.

La repressione dell'agitazione studentesca contribuì a esacerbare gli animi del ceto borghese, cui in gran parte appartenevano gli studenti, a ingigantire il desiderio di riforme, e funzionò quindi da possente appoggio all'attività dei liberali, che divenne sempre più aperta e quasi sfacciata, approfittando anche del fatto che

«[...] il governo [...] ritornò ancora più inerte, senza forza contro il dilagare delle idee, illudendosi sempre, ma più pauroso. [...] E si lasciò andare per viltà alla estrema tolleranza permettendo che i cittadini si riunissero pubblicamente e manifestassero le loro speranze, non impedendo la diffusione degli opuscoli e dei fogli volanti [...]. Ma il governo si può dire che più non esisteva» (Torta, 1908: 71).

Cesare Balbo redasse nei giorni tra il 9 e il 17 gennaio un breve testo: Dello stato attuale del Piemonte ${ }^{83}$, in cui descrive e analizza magistralmente la situazione del regno. In esso egli vede «un partito e una fazione», precisando che partito è «una parte ragguardevole dei cittadini di uno Stato riuniti dall'opinione e pei fatti, onde procacciare con mezzi legittimi una mutazione di ordini», mentre fazione è «la riunione di quelli che promuovono le mutazioni con mezzi non provveduti dalle leggi». Quindi «fazione lecita è cosa rarissima, fazione legittima non si può dir mai» (Passamonti, 1927: 306). Dopo aver sommariamente diviso l'opinione pubblica in tre campi: costituzionali, Carbonari e governo, concludeva:

«Dalle descrizioni fatte del partito e della fazione, quella del governo è come inutile a farsi. Non ha partito: se gli si dà una spinta, non ha dove si appoggi [...]: sta, perché non gli è stata data tuttavia quella spinta, ma egli crede che non gli si dia, perché sta... Ė composto di poche persone [...] non si informano delle opinioni $[\ldots]$, non conoscono lo stato presente della nazione [...]. Il maggior inconveniente delle società segrete è quello di non rinnovare le idee [...]. Il Governo presente ha tutti gli inconvenienti di un comitato centrale di società segrete; ma non ha né le informazioni, né i mezzi di esecuzione,

82. Per l'agitazione degli studenti si veda il saggio di Egidi (1926: 103-247), anche GiglioTos (1906).

83. Lo scritto di Balbo («Son pagine 9» osservava Ricotti, 1856: 438) faceva parte dello scomparso vol. XIII dei ms. in $4 .{ }^{\circ}$. Abbiamo per fortuna il testo, pubblicato per la prima volta da Avetta (1914, appendice), lo ripubblicò Passamonti (1927: 306-309). 
che hanno le società. [...] Tra un governo che non vede, un partito che non fa, ed una fazione che vede e fa, chi vincerà?» (Passamonti, 1927: 308-309).

A conferma di questa analisi proprio in quei giorni si cementò l'alleanza tra l'ala moderata del movimento, i Federati torinesi prevalentemente aristocratici guidati da Santarosa, l'elemento democratico carbonaro e i congiurati di Alessandria, anch'essi schierati su posizioni radicali.

La rivoluzione di Napoli fu il fattore determinante nella scelta della richiesta della Costituzione di Cadice da parte di tutto il movimento liberale piemontese, superando le precedenti divisioni tra fautori della Carta francese, siciliana o di quella spagnola. Come scrisse Santarosa:

«Se i liberali piemontesi non videro tutti con piacere la costituzione prescelta da' Napoletani, la maggior parte di essi però riconobbe nella loro rivoluzione una di quelle grandi occasioni [...] di riprendere onoratamente il loro posto sulla scena politica. [...] I Napoletani aveano rivendicato i loro diritti, erano nostri fratelli; noi non potevamo abbandonarli senza venir meno al dovere, all'onor nazionale» (Santarosa, 1920a: 102-103).

Quasi con le stesse parole un altro patriota, che sarà più tardi esule in Spagna e quivi difensore del governo costituzionale, Carlo Beolchi, espone la situazione:

«Le opinioni dei federati intorno alla costituzione da proclamarsi erano varie. [...] La rivoluzione di Napoli del 1820 compose ogni differenza d'opinioni e determinò la scelta della costituzione. I Napoletani avevano proclamato la costituzione di Spagna del 1812. Volendo noi fare causa comune con Napoli, [...] altra scelta a noi non rimaneva che la costituzione di Spagna, e questa si convenne di proclamare» (Beolchi, 1864: 288).

Si è visto come gli animi fossero ormai in ebollizione e pronti all'azione alla minima provocazione. A gettare olio sul fuoco dell'imminente rivolgimento si aggiunse, il 28 febbraio, il sequestro su una carrozza in arrivo da Parigi di alcune lettere del Principe della Cisterna e di Luigi Angeloni per importanti personaggi dell'aristocrazia, da cui emergeva con chiarezza l'ampiezza della cospirazione e, soprattutto, come essa fosse conosciuta, approvata e vista con simpatia da Carlo Alberto (Lemmi, 1926: 3-99). Ciò spiega come l'azione contro i congiurati abbia loro permesso di sottrarre o distruggere i documenti più pericolosi, che avrebbero consentito l'arresto di altri coinvolti, ma non avrebbero mancato di compromettere ancor più gravemente il principe ereditario, impedendo così -cosa cui tutti, sia reazionari sia liberali, erano avversi- che il trono andasse a un Savoia, pur se di un ramo collaterale.

Molto è stato scritto a proposito del reale coinvolgimento di Carlo Alberto nella cospirazione del 1821, della sua possibile adesione alla Carboneria o ai Federati, del suo iniziale consenso ai piani dei congiurati e del successivo 
mutamento d'opinione, che alcuni definirono un tradimento. Non si contano gli storici, ahimé in qualche caso dovrei meglio dire gli agiografi, che hanno strenuamente difeso la figura del Principe di Carignano anche contro l'evidenza schiacciante dei documenti ${ }^{84}$, finché altri, più seriamente preoccupati del rispetto della verità, non provvidero a rimettere tutta la questione sul piano della correttezza scientifica ${ }^{85}$. Quello che a me preme notare qui è come, dopo l'arresto del Principe della Cisterna e dei corrispondenti suoi e di Angeloni, il governo, anziché intensificare l'azione repressiva per smascherare tutta la rete cospirativa, «non disturbò più nessuno, e tutte le misure si restrinsero a far percorrere la città da qualche pattuglia di cavalleria» (Torta, 1908: 84).

In realtà a Corte si era molto preoccupati; le lettere del Principe della Cisterna e gli altri documenti sequestrati avevano dato finalmente al re l'idea della dimensione della cospirazione e reso chiaro come i più bei nomi della sua aristocrazia e del suo esercito - di cui era particolarmente fiero- vi fossero coinvolti. Febbrili discussioni si tennero tra i reali, Prospero Balbo -che intanto si adoperava a occultare e sminuire il coinvolgimento di Carlo Alberto- e altri ministri e alti dignitari; qui di nuovo si vide con chiarezza come la regina fosse buona conoscitrice della letteratura giuridica del tempo. Una notazione del diario di Prospero Balbo, datata 9 marzo, è significativa:

«Restituisco alla Regina il libro di Haller contro la Costituzione Spagnuola, [...]. Le parlo di quella costituzione secondo il parer mio, cioè come pessima: le dico che la buona causa, sostenuta da Haller, potea trattarsi meglio: le addito il libro del Lanjunais, sebbene autore poco monarchico, contro quella medesima costituzione» ${ }^{86}$.

84. Si vedano soprattutto alcune delle lettere sequestrate nella carrozza e agli arrestati in Lemmi (1926: 41-49).

85. Le pubblicazioni apologetiche iniziarono presto: (Andreozzi, 1850; Cibrario, 1861; 1865; Costa, 1889; 1890; Perrero, 1889; Masi, 1890). Lintento decisamente agiografico si fece evidente nelle opere pubblicate tra le due guerre mondiali: ne fu alfiere Luzio (1923), nelle note e commenti alla sua traduzione dell'opera di Santarosa, De la révolution piémontaise, fedelmente seguito dai suoi allievi, come ad esempio Passamonti (1930), e Colombo (1921). In tempi più recenti si è avuta la massiccia biografia, apologetica ma ben documentata e costruita secondo solidi canoni scientifici, di Rodolico (1931; 1936; 1943). Lopera, poi ristampata nel 1948, provocò una vivace polemica, iniziata con decisione nel 1938 da Guido Porzio nella rasssegna «Studi albertini e alterazioni programmatiche nella storia del Risorgimento», pubblicata sulla Nuova Rivista Storica. Nel 1940 poi Omodeo pubblicava a Torino per i tipi di Einaudi La leggenda di Carlo Alberto nella recente storiografia, poi riedita in Difesa del Risorgimento, 1951, in cui, demolita con argomenti inconfutabili l'impostazione agiografica, sistemava in modo sostanzialmente definitivo l'interpretazione della personalità di Carlo Alberto. Su Luzio e la sua scuola anche (Gramsci, 1975: 2071-2076). Una biografia complessivamente favorevole al sovrano è quella di Brignoli (2007).

86. Diario di avvenimenti del Conte P.B., Venerdì 9 marzo (Passamonti, 1927: 300). 
Il libro di Haller è l'edizione per i tipi di Soliani di Modena della traduzione in francese, fatta dall'Autore, del suo Über die Konstitution der Spanischen Cortes, pubbblicato per la prima volta a Winterthur nel 1820 (Haller, 1820). Questo libretto del politico conservatore svizzero, ferocemente avverso alla Costituzione di Cadice, riscosse in Italia una fortuna immensa; con titoli leggermente diversi ebbe, nel solo 1821, cinque edizioni in italiano ${ }^{87}$. Nel 1822 altre due: una -dopo la reazione e la repressione- a Napoli, l'altra a Venezia ${ }^{88}$. Altre ancora nel 1823 e negli anni seguenti. Lapprezzamento della regina per l'operina dello Haller, che afferma che le Costituzioni sono «una parola funebre, che mena seco rovina, e spande odor di cadavere», «un veleno nelle Monarchie, perciocché presuppone una base democratica, organizza la guerra intestina e crea due elementi lottanti a vita e morte l'un contro l'altro ${ }^{89}$, è sintomatico dell'ambiente ideale e culturale in cui Prospero Balbo tentava invano di spiegare che i tempi erano mutati e che servivano riforme, anche se meditate e moderate.

Il 6 marzo ebbe luogo il celebre colloquio tra Carlo Alberto e quattro capi del movimento: Santorre de Rossi conte di Santarosa, il marchese Carlo Asinari di San Marzano, il conte Guglielmo Gribaldi Moffa di Lisio e il cavaliere Giacinto Provana di Collegno. Un quinto uomo era presente: solo molti anni dopo si seppe ch'era Roberto d'Azeglio. I cospiratori esposero il progetto al Principe e alfine Santarosa disse: «Principe, tutto è pronto, non s'aspetta più che il vostro consenso». Per usare ancora le sue parole: "Carlo Alberto dié quel consenso: il conte di Santarosa gli tese allora la mano con la franchezza di un libero cittadino $»^{90}$.

La sera del 7 il Principe di Carignano si rimangiò la promessa, ma il giorno dopo «biasimava [i congiurati] di abbandonare troppo facilmente l'impresa». A questo punto, diffidando del Principe, i cospiratori fissarono la nuova data

87. Analisi della Costituzione delle Cortès di Spagna, Modena, Eredi Soliani, 1821, con la lettera di Haller che ne annuncia il ritorno al cattolicesimo; altra edizione con lo stesso titolo, tradotta dal francese da Francesco Grimelloni d'Austria, Modena, Dalla Società Tipografica, 1821; Analisi della Costituzione delle Cortès di Spagna, Imola, Tipografia del Seminario, 1821; Sulla costituzione spagnola, Bologna-Modena, Gamberini e Parmeggiani, 1821; Analisi della Costituzione delle Cortès di Spagna, Torino, Pomba, 1821 (tradotta dal tedesco).

88. Della costituzione delle cortes di Spagna... Traduzione dal tedesco nel francese ed ora trasportata nell'idioma italiano da G.A.P., Napoli, Porcelli, 1822; Sulla Costituzione spagnola, Venezia, Tip. G. Molinari, 1822.

89. Analisi della Costituzione delle Cortès di Spagna, Modena, Eredi Soliani, 1821: 179 e 223-224.

90. Sul colloquio del 6 marzo e gli sviluppi dei giorni seguenti cfr., oltre il più volte citato testo di Santarosa (1920a: 118-122), l'articolo di Colombo, (1921), che costituisce la ricostruzione più completa dei fatti, anche se, come detto più sopra viziata dall'intento apologetico a favore di Carlo Alberto. 
al 10 marzo, senza dirlo a Carlo Alberto, che ripeté il suo assenso, mentre al contempo prendeva misure militari per rendere impossibile ogni sollevazione a Torino. Resisi conto di ciò Santarosa e gli altri decisero di non rischiare e di fermare tutto il moto; il momento fu drammatico:

«Non più speranza; i mezzi che ci restavano, più non offrivano ragionevoli probabilità di successo. Tentare una rivoluzione il cui esito rimanesse dubbio per più di cinque o sei giorni, sarebbe stato lo stesso che consegnare la patria agli Austriaci. [...] Era pur forza decidersi: i congiurati credettero dover fare il sacrificio de' loro progetti agl'interessi della patria» (Santarosa, 1920a: 122).

Ma i messaggeri spediti in provincia guingono troppo tardi, e «sul mattino del giorno 10 si sparge d'improvviso la notizia a Torino che la guarnigione di Fossano s'è messa in marcia». Immediatamente i quattro capi partono, chi verso Vercelli, chi verso Pinerolo. Intanto anche ad Alessandria erano insorti militari e civili, occupando la Cittadella e assumendo il totale controllo della città, ove fu nominata una giunta provvisoria di borghesi e militari. La guarnigione di Pinerolo fu convinta da Lisio e Santarosa: «in cinque minuti 300 cavalleggieri partivano di corsa» alla volta di Carmagnola, e quindi di Asti, dove giunsero l'11 marzo a mezzogiorno. «Entrarono uniti nella città in mezzo ad una immensa folla, che attonita in sulle prime, non tardò a confondere il suo col giubilo dei soldati». Le truppe costituzionali si diressero quindi su Alessandria, dove giunsero il 12.

«Venne proclamata la costituzione sulla gran piazza, ed inalberato il vessillo tricolore. Il popolo dié libero sfogo alla gioia, la felicità che traspariva da tutti i volti, [...] offriva un commovente spettacolo: ma quel popolo saggio non recò insulto al dolore di alcune famiglie ligie alla monarchia assoluta» (Santarosa, 1920a: 122-126).

A Torino la capitale era percorsa da rumori e voci. La mattina del 10 marzo, sabato, giunse notizia della riuscita insurrezione di Alessandria e della costituzione della giunta provvisoria; ciò spronò all'azione i patrioti, il governo continuava nella passività ${ }^{91}$.

Il giorno 11, dalle due alle cinque del pomeriggio, Prospero Balbo, in una concitata e drammatica riunione col re e con gli altri ministri, tentò per l'ultima volta di evitare il peggio, cercando di convincere il sovrano a concedere una Costituzione, fatta preparare quella mattina dal suo segretario sulla base della siciliana del 1812, e che per la prima volta introduceva il termine Statuto, usato poi durante tutto il Risorgimento.

91. Sull'insurrezione a Torino Segre (1926: 251-327, e per le responsabilità governative, 251-254). 
La discussione tra la coppia reale, Balbo e egli altri ministri era sfociata nella conclusione che a una Costituzione bisognasse giungere, e alfine il re chiese a Balbo di stendere una minuta di promulgazione, che venne così redatta:

«Sua Maestà dà ai suoi popoli la costituzione inglese nel modo, che sarà compilato dal Parlamento ed approvato dal Re, con due espresse riserve, cioè di quanto riguarda la religione e la successione al trono su' quali due punti Sua Maestà non vuole sia cangiato nulla agli ordini attuali» (Passamonti, 1927: 324-332).

Dopo lunga discussione sui termini della minuta, il re approvò la stesura definitiva, così:

«Il Re ammette per li suoi stati di terraferma la costituzione inglese con due riserve, cioè di quanto riguarda la religione e la successione al trono su' quali due punti Sua Maestà non intende sia cangiato nulla agli ordini attuali» (Passamonti, 1927: 331).

Le eccezioni introdotte nella minuta e nel testo sono interessanti, perché mostrano come Prospero Balbo e il monarca intendessero continuare a garantire la libertà di culto a valdesi ed ebrei, e volessero assicurare la successione a Carlo Alberto. Per converso, ciò mostra anche come i rivoluzionari che volevano la Carta spagnola non pensassero che essa avrebbe introdotto una misura certamente illiberale dando alla religione cattolica il primato assoluto (art. 12), e che avrebbe trasmesso il trono alle figlie della regina, anziché, come essi volevano, al Principe di Carignano.

Non è possibile sapere cosa sarebbe accaduto se la dichiarazione del re fosse stata emanata, ma è probabile, dato il fortissimo legame del popolo con la casa regnante, che il corso degli avvenimenti sarebbe stato radicalmente mutato. Tuttavia, proprio quando gli sforzi di Prospero Balbo sembravano coronati da successo, anche se non nella misura e nei modi da lui desiderati, giunse di ritorno da Lubiana il ministro degli Esteri, San Marzano, che informò sulla volontà delle potenze colà riunite: «Niuno voler esigere dai Principi che diano costituzioni, anzi le tre Potenze non voler permettere che i Principi d'Italia siano indotti a darla; ed ora, se la dessero, non volerli supporre in libertà $»^{92}$. La mattina del 12 si era deciso che il re lasciasse Torino per Asti e poi Nizza, dopo aver lanciato due proclami, uno all'esercito, l'altro al paese, quando «[...] all'una pomeridiana rintronarono tre colpi di cannone: la bandiera italiana era stata inalberata sui bastioni della cittadella dalla truppa di guarnigione» (Santarosa, 1920a: 128) ${ }^{93}$.

92. Diario di avvenimenti del Conte P.B., Domenica 11 marzo.

93. Per l'insurrezione alla cittadella di Torino si veda Colombo (1926). La versione di un protagonista si trova in Garda (1879). 
È bene precisare che la bandiera cui si fa riferimento era sì tricolore, ma -spiega lo stesso Santarosa- «nera, rossa ed azzurra [...] simile alla bandiera napoletana» (Santarosa, 1920a: 128), si trattava perciò dei colori carbonari. Vittorio Emanuele I tentò invano di dissuadere i soldati e il popolo dai loro propositi sediziosi mandando alla Cittadella Carlo Alberto. Il Principe conferì con un soldato semplice, che dagli spalti gli disse che gli insorti volevano la Costituzione di Spagna e la guerra all'Austria ${ }^{94}$. Dopo altre lunghe e convulse discussioni il re, assolutamente contrario a concedere alcun tipo di Costituzione, ma che non voleva reprimere con la violenza e nel sangue un moto ormai vastamente diffuso in tutti gli strati della popolazione, decise di abdicare in favore del fratello Carlo Felice. Poiché questi al momento si trovava a Modena venne conferita la reggenza a Carlo Alberto. A mezzanotte del 12 marzo «si soscrive l'atto di abdicazione» (Thaon, 1871: LI-LII) e Carlo Alberto firma il testo di una notificazione al Paese, da pubblicarsi al momento della sua assunzione della reggenza, la mattina del 13 (Thaon, 1871: LII).

La notizia dell'abdicazione causò grande costernazione tra gli insorti, come si può giudicare dalle parole di Santarosa:

«O notte del 13 marzo 1821 ! Notte fatale al mio paese, che tutti ne immerse nello squallore, che privò la libertà piemontese dell'appoggio di tante braccia e dileguò le nostre più care speranze come un sogno! Certo la patria non muore mai: ma i nostri cuori identificavano trono e patria, anzi Vittorio Emanuele e patria. [...] Ed i giovani promotori di quella rivolta militare aveano più d'una volta esclamato: 'e ci perdonarà bene d'averlo fatto re di sei milioni d'italiani!'» (Santarosa, 1920a: 131).

A quel punto gli insorti si ritrovavano come interlocutore Carlo Alberto, di cui era noto il carattere ambiguo e di cui ormai sapevano di non potersi fidare, $\mathrm{e}$ intanto la condizione irrinunciabile per far rientrare l'insurrezione nei binari della legalità era divenuta la concessione della Costituzione spagnola, e di quella soltanto.

Ancora Santarosa lo dice chiaramente: «A stento avrebbe Vittorio Emanuele l'11 marzo potuto dare un'altra costituzione; lo sperarlo il 13 era un ingannarsi a partito. Il popolo si attruppava nelle strade, sulle piazze; ogni ritardo faceva stupire» (Santarosa, 1920a: 132).

Fu così che la force des choses -come già in molti altri casi- indirizzò la rivoluzione piemontese verso un risultato ben diverso da quello che molti dei suoi ideatori avevano progettato, risultando in questo, come lucidamente giudicò Metternich, «un événement tout a fait extraordinaire», poiché, continuava

94. A.M.D.G., in Manno (1879: 121) e, nella stessa opera, il memoriale del generale Gifflenga, 113-114. 
lo statista austriaco, «personne ne s'y reconnaît. Les uns ne la veulent pas et la font, les autres la voudraient mais travaillent contre elle; c'est une vraie tour de Babel...» (Metternich, 1880-1884, III: 463).

Intanto, mentre a Torino si esitava, i liberali del resto del regno agivano: lo stesso giorno 13 la Costituzione veniva proclamata in centri importanti come Ivrea e Biella (Torta, 1908: 123). Visto come la situazione andasse peggiorando il reggente, non volendo da solo assumersi la pesante responsabilità della decisone, chiese il parere delle autorità municipali e di altri notabili civili e militari, e pretese una dichiarazione scritta in cui essi affermavano:

«[...] che le attuali circostanze sono sì gravi, il pericolo di una guerra civile sì imminente, il voto del popolo così altamente espresso, che noi pensiamo essere indispensabile per la salvezza pubblica e per la necessità delle cose, che venga promulgata la costituzione spagnuola $»^{95}$.

Alcuni ex ministri, come Thaon di Revel e Vallesa, rifiutarono di firmare la dichiarazione, ma il parere dei notabili e dei comandanti militari, timorosi di un bombardamento da parte della Cittadella, fecero sì che si decidesse per la Costituzione di Cadice. «Alle otto di sera il principe stesso lo annunziò al popolo dal balcone del suo palazzo» (Santarosa, 1920a: 133). L'entusiasmo popolare esplose irrefrenabile, la città si illuminò a festa, si videro cittadini abbracciarne altri mai visti né conosciuti, «studenti, soldati, popolani erano amici tutti» (Torta, 1908: 126).

Come già a Napoli la Costituzione conobbe una popolarità smisurata: nella sola Torino si diffusero in pochi giorni ventimila esemplari del testo edito da Pomba, e altre migliaia si distribuirono in provincia, «ed i librai non ne aveano esemplari bastanti a soddisfar le richieste» (Santarosa, 1920a: 133). Anche a Torino, come a Napoli, fu pubblicato, per i tipi di Domenico Pane, un Catechismo politico ordinato a mente della Costituzione della Monarchia Spagnuola Ad uso delle scuole elementari e per istruzione del Pubblico. È, come quello napoletano, la pedissequa traduzione di un testo spagnolo in 17 lezioni, quindi inutile nella situazione italiana. Di particolare interesse, in fondo al volume, la Tavola de' diritti, e dei doveri degli Spagnuoli secondo la Costituzione, che elenca i diritti inalienabili dell'uomo, dichiarato eguale riguardo agli stessi: la libertà, la sicurezza e la resistenza all'oppressione; proclama la sovranità della nazione e il suo diritto a legiferare e imporre tributi, riaffermando il primato della legge che è «l'unico segnale della volontà generale, e la regola suprema di tutti i poteri particolari» ${ }^{96}$.

95. Per il testo integrale, e i nomi dei firmatari, Beolchi (1864: 459).

96. Catechismo politico ordinato a mente della Costituzione della Monarchia Spagnuola Ad uso delle scuole elementari e per istruzione del Pubblico, Torino, Domenico Pane, 1821, p. 61. 
Anche dopo aver concesso la Costituzione Carlo Alberto non mutò il modo di procedere ambiguo ed esitante: il 14 marzo -avendo intanto mandato a Modena il suo scudiero Sylvain Costa de Beauregard con una lettera per Carlo Felice-formò un governo di soli liberali «persone oneste, intelligenti, stimatissime; ma non dotate dell'energia imperiosa che è necessaria in così difficili momenti» (Torta, 1908: 131); insieme al governo venne costituita una Giunta, prima di 14 poi di 28 persone, in attesa dell'elezione di un parlamento. E di fronte alla Giunta il 15 Carlo Alberto giurò sui Vangeli di osservare e far osservare la Costituzione spagnola. Ma insieme a queste azioni che mostravano una certa decisione di proseguire sulla strada costituzionale altre, di segno diverso e talvolta opposto, indicavano la fragilità e l'incostanza del carattere del reggente: ricevendo i patrioti lombardi si mostrò con loro freddissimo, i preparativi guerreschi -fondamentali dato che la guerra con l'Austria era complemento indispensabile di tutta l'iniziativa rivoluzionaria- erano estremamente lenti e limitati. «Non è così -dice Santarosa- che poteva imprendersi la guerra fra otto giorni», e soggiunge: «Nelle guerre politiche vi sono preziosi momenti che, trascorsi, si perdono per sempre; Carlo Alberto sembrò guardarsi bene dall'afferrare quello che si offriva al suo coraggio», e giunge all'amara conclusione: «Il principe di Carignano si attenne in ogni cosa ad un sistema del tutto in armonia colla paurosa fiacchezza dell'animo» (Santarosa, 1920a: 137).

La controrivoluzione intanto stava muovendo i primi passi a Novara, anche grazie all'ingenuità di Carlo di San Marzano, che, entrato in città alla testa dei suoi dragoni, dopo aver persuaso il governatore della divisione conte Della Torre a schierarsi per la Costituzione, per dare esempio di disciplina militare gli si sottomise, lasciandogli così la possibilità di gestire il comando di quella importante piazza militare, fondamentale per la vicinanza al confine con il Lombardo-Veneto. Della Torre, pur di moderati sentimenti costituzionali di tendenza inglese, aveva un carattere debole e ondeggiante (Des Ambrois, 1901:100)97, ma quando il 16 marzo ricevette da Carlo Felice l'ordine di costituire in città una Luogotenenza generale del regno direttamente dipendente dal sovrano, non esitò a obbedire e il 17 comunicò la sua decisione al reggente, utilizzando come messaggero il colonnello Adolphe de Maistre.

Il messaggio di Della Torre gettò Carlo Alberto in una grave crisi di scoraggiamento, che crebbe a dismisura il 18 , ricevendo da Modena la risposta di Carlo Felice, che non era una lettera, bensì un violentissimo proclama datato

97. Sul carattere di Della Torre se ne veda il giudizio di Carlo Felice in una lettera a Vittorio Emanuele I: «...je le crois sincèrement bon, mais d'une faiblesse extrême, et ce n'est qu'à force de l'avoir harcelé, fulminé et même menacé que j'ai réussi à lui faire faire tout ce qu'il a fait». (Bianchi, 1865, II: 341). 
16 marzo che, senza nemmeno nominare il reggente, dichiarava ribelli i costituzionali, annullava gli atti della reggenza, incitava alla resistenza e all'unione i rimasti fedeli e prometteva l'intervento alleato per ristabilire l'ordine. A tutta prima il Principe di Carignano ebbe uno scoppio di collera e parve volersi ribellare all'ingiunzione dello zio, ma quando lo scudiero latore del proclama gli comunicò che Carlo Felice, come unico messaggio al nipote, aveva detto, parlando di lui con l'ufficiale: «Se gli resta una goccia di sangue reale nelle vene deve recarsi a Novara e attendere colà i miei ordini», si calmò e convocò una riunione generale di tutti i ministri disponibili, vecchi e nuovi.

Dopo una lunga discussione di carattere giuridico -il proclama di Carlo Felice era per molti versi illegale ${ }^{98}$ : in esso il re non dichiarava di assumere il titolo regale, ma pretendeva di esercitarne la piena autorità, annullava gli atti della reggenza ma non la revocava ${ }^{99}$ - il consesso decise di non promulgare l'editto, e di pubblicare un manifesto al Paese in cui si diceva che il re aveva risposto «in modo a farci credere non essere la Maestà Sua pienamente informata della situazione», e che si era quindi deciso di inviare una delegazione a Modena per aggiornare pienamente il sovrano, certi così di ottenere «quell'esito felice che ci promette il suo cuore, naturalmente propenso alla felicità dei suoi popoli» (Gualterio, 1861, II).

In realtà ormai Carlo Alberto stava preparando la fuga a Novara, città verso cui intanto indirizzava quante più truppe riuscisse a sottrarre all'influenza dei dirigenti costituzionali, che tentava di tenere a bada nominando la sera 21 marzo Santarosa reggente del ministero della Guerra, in sostituzione del cavaliere di Villamarina, dimessosi perché malato. Quella stessa notte, accompagnato dall'artiglieria leggera, dai cavalleggeri di Savoia e dal reggimento Piemonte Reale cavalleria, il reggente si rifugiava a Novara, dando forma compiuta a quello che è difficile non definire un tradimento.

Nei pochi giorni di respiro concessi ai costituzionali frenetica fu l'attività di Santarosa nel reclutamento e nell'organizzazione militare, così come quella politica, fatta di proclami e di appelli, non solo alle popolazioni del regno perché si stringessero attorno al governo e alla Giunta nell'appoggio alla Costituzione, ma anche ai Lombardi, perché insorgessero e aiutassero i fratelli piemontesi nell'imminente guerra di liberazione dallo straniero.

98. Ogni editto regio doveva essere trasmesso dall'Ufficio di Stato al ministro delle Finanze, da qui al gran cancelliere per essere interinato, e finalmente agli Intendenti delle province che avrebbero provveduto alla pubblicazione. RR. Costituzioni del Piemonte, Tit. I, Lib. 2, § 17; Tit. 2, Capit. I, Lib. 2, § 5; Tit. 17, § 3.

99. Una dotta argomentazione giuridica sull'editto di Carlo Felice si trova nell'opuscolo del conte Alerino Palma, già magistrato in Piemonte (1829: 25-28). 
Il dramma finale della rivoluzione piemontese si concluse l' 8 aprile col breve e sfortunato scontro alle porte di Novara dei costituzionali con gli austriaci, e l'ingresso a Torino, il 10, del generale Della Torre. Anche in Piemonte, come pochi giorni prima nelle Due Sicilie, si scatenò la brutale reazione -solo le condanne a morte furono novantasette!- contro chiunque fosse anche solo lontanamente sospettato di aver simpatizzato per gli insorti, e anche qui si ebbe il triste esodo di centinaia di patrioti, in gran parte diretti in Spagna, dove molti di loro avrebbero di lì a poco combattuto eroicamente, spesso insieme a esuli napoletani, in difesa di quella stessa Costituzione per cui avevano dovuto abbandonare la patria e la famiglia.

Redigendo il suo diario, al 20 aprile 1821, Clemens von Metternich liquidava cinicamente in tre scarne righe l'epilogo dei rivolgimenti italiani che ho a grandi linee descritto: «Dans l'espace de six semaines, nous avons fini deux guerres et étouffé deux révolutions. Espérons que la troisième, celle qui a éclaté du coté de l'Orient, ne sera pas plus heureuse» (Metternich, 1880-1884, III: 465). Si sbagliava in quest'ultimo auspicio, giacché la rivoluzione orientale cui alludeva era quella dei patrioti greci, che avrebbe da un lato condotto alla creazione del primo nucleo di uno stato ellenico indipendente, iniziando così il progressivo disfacimento dell'Impero Ottomano, dall'altro avrebbe segnato l'inizio della fine della Santa Alleanza, di fatto sancita poi al Congresso di Verona nell'ottobre del $1822^{100}$.

Ma lo statista austriaco, lieto dei successi ottenuti in gran parte per merito suo, dalle potenze coalizzate a danno dei patrioti italiani, non era per nulla convinto che la vittoria fosse definitiva. Scrivendo da Lubiana al conte di Bombelles il 29 aprile 1821, diceva tra l'altro:

«La Providence a permis, qu'en moins de cinq semaines deux révolutions, qui avaient éclaté aux deux extrémités de l'Italie [...] fussent écrasées par nos efforts directs [...]. Nous ne pourrons pas nous dissimuler cependant que ce n'est qu'un premier pas vers le bien, et que, pour compléter l'ouvrage, il nous reste peut-être plus à faire que nous n'avons fait jusqu'ici. Ce serait effectivement se livrer à une dangereuse illusion, que de croire l'esprit révolutionnaire $[\ldots]$ entièrement anéanti [...]. Le mal n'est que comprimé $[. .$.$] et si l'on ne$ profite pas de cette circonstance favorable pour l'extirper entièrement, nous ne tarderons pas à lui voir [...] reprendre sa pernicieuse activité. C'est donc la prompte et entière répression de ce mal dangereux que doivent avoir en vue aujourd'hui tous les gouvernements de la péninsule» (Bianchi, 1865, II: 311).

100. Il migliore e quasi unico resoconto del Congresso lo si veda in Chateaubriand (1838). 


\section{Conclusione}

Come si sa, la repressione invocata da Metternich non mancò negli Stati italiani, a questa stessa repressione si sarebbero dedicati, nel 1823, i «100.000 figli di San Luigi» accorsi a schiacciare la libertà della Spagna in ossequio alle decisioni prese l'anno prima a Verona. E in quel continuo rincorrersi e abbracciarsi di destini tra Italia e Spagna di cui ho parlato all'inizio sarebbero stati centinaia gli Italiani esuli caduti per difendere la terra che li aveva fraternamente accolti dopo le loro sfortunate rivoluzioni. Alcuni di loro erano presenti alla battaglia del Trocadero, a Cadice, culla della Costituzione, mentre con i Francesi combatteva Carlo Alberto, schierato con i reazionari per riabilitarsi agli occhi dello zio e riacquistare così il diritto di succedergli sul trono. Molti degli Italiani superstiti, che dovettero naturalmente riprendere la via dell'esilio, o torneranno poi in Italia a lottare per l'indipendenza mettendo a frutto le esperienze militari accumulate in Spagna, o di quella esperienza lasceranno duratura traccia nelle opere teoriche dedicate a quel tipo di guerra popolare resa celebre in Europa dall'eroismo spagnolo, e che da allora in molte lingue si chiamò "guerriglia» ${ }^{101}$.

Per chiudere questa serie di richiami alla corrispondenza e correlazione Spagna-Italia che ho spesso citato, non posso alfine non ricordare il motto «Oggi in Spagna, domani in Italia», lanciato da radio Barcellona nel 1936 da Carlo Rosselli, esortando non senza frutto gli antifascisti italiani ad accorrere a difendere numerosi la Repubblica ${ }^{102}$. E di nuovo, come era accaduto oltre cent'anni prima, gli italiani superstiti di quella guerra avrebbero poi messo a frutto l'esperienza appresa in terra di Spagna per combattere sulle nostre montagne contro nazisti e fascisti.

\section{Bibliografía}

ACETO, Giovanni (1827). De la Sicile et de ses rapports avec l'Angleterre à l'époque de la constitution de 1812. Paris: Ponthieu. Prima edizione italiana (1848). Della Sicilia e dei suoi rapporti con l'Inghilterra all'epoca della costituzione del 1812. Palermo: Olivieri. Ristampata (1970). Palermo: Ed. della Regione Siciliana.

101. Citiamo per tutti il conte Carlo Bianco di Saint Jorioz, massimo teorico italiano della «guerra per bande», che pubblicò a Marsiglia nel 1830 i due volumi su Della guerra Nazionale d'insurrezione per bande applicata all'Italia-Trattato dedicato ai buoni Italiani da un amico del paese. Mi permetto a questo proposito di rimandare a (Scotti Douglas, 2007). Per la storia e l'evoluzione della guerriglia (Scotti Douglas, 2000; 2001).

102. Carlo Rosselli, Oggi in Spagna, domani in Italia, discorso del 13 novembre 1936 a Radio Barcellona, pubblicato il 27 dello stesso mese da Giustizia e Libertà. Lo si veda ora in Rosselli (1992: 424-428). 
ALBERTI, Annibale (1911). Le Costituzioni nel Risorgimento. En Le Assemblee del Risorgimento, 15 vol. Roma: Tip. della Camera dei Deputati.

ALBERTI, Annibale (ed.) (1926-1931). Atti del Parlamento delle Due Sicilie 18201821, 5 vol. Bologna: Zanichelli.

ANDREOZZI, Alfonso (1850). Vita di Carlo Alberto. Torino: Crivellari.

AVETTA, Maria (1914). Le relazioni di Carlo Alberto coi liberali prima del Ventuno. Rassegna storica del Risorgimento italiano (I), 5, 754-758.

AVETTA, Maria (1924). Al Congresso di Lubiana coi Ministri di Re Vittorio Emanuele I. Il Risorgimento italiano, vol. XVII, fasc. I-II, 218.

BALBO, Cesare (1856). Autobiografia di Cesare Balbo, scritta nell'aprile 1844. En Ercole RICOTTI. Della vita e degli scritti del conte Cesare Balbo. Rimembranze con documenti inediti. Firenze: Le Monnier.

BALBO, Cesare (1859). Lettere politiche di Cesare Balbo, al signor D., IV, Delle rivoluzioni e delle riforme. En Lettere di politica e letteratura. Torino: Unione Tipografico-Editrice.

BALBO, Cesare (1926). Memorie del conte Cesare Balbo sulla rivoluzione del 1821 in Piemonte. En Eugenio PASSAMONTI, Cesare Balbo e la Rivoluzione del 1821 in Piemonte, in Biblioteca di Storia Italiana Recente (1800-1870), vol. XII, La rivoluzione piemontese dell'anno 1821. Nuovi documenti a cura di Eugenio PASSAMONTI, Alessandro LUZIO, Mario ZUCCHI. Torino: Bocca.

BALBO, Cesare (1935). Scritti militari, a cura di Eugenio PASSAMONTI. Roma: Edizioni Roma.

BATTISTA, Anna Maria (1976). Aspetti del tradizionalismo italiano nell'età della Restaurazione. En La Restaurazione in Italia. Strutture e ideologie. (223-249). Roma: Istituto per la storia del Risorgimento italiano.

BEOLCHI, Carlo (1864). Il Piemonte nel 1821. La Rivista Contemporanea, 132, 288.

BIANCHI, Nicomede (1865). Storia documentata della diplomazia europea in Italia, 8 voll. Torino: Unione Tipografico-Editrice.

BIANCO, Giuseppe (1902). La Sicilia durante l'occupazione inglese. Con appendice di documenti inediti degli Archivi di Londra, Firenze e Palermo. Palermo: Reber.

BLANCH, Luigi (1945) Scritti storici, 3 vol. Bari: Laterza.

BRIGNOLI, Marziano (2007). Carlo Alberto ultimo re di Sardegna 1798-1849. Milano: Istituto per la storia del Risorgimento italiano.

BROFFERIO, Angelo (1849). Storia del Piemonte dal 1814 ai giorni nostri, 4 vol. Torino: Stab. Tip. Fontana.

BUSAALL, Jean-Baptiste (2015). Les origines du pouvoir constituant en Espagne, la Constitution de Bayonne (1808). En Fernando GARCÍA SANZ, Vittorio SCOTTI DOUGLAS, Romano UGOLINI, José Ramón URQUIJO GOITIA (eds.). Cadice e oltre: costituzione, nazione e libertà. La carta gaditana nel bicentenario della sua promulgazione (57-90). Roma: Istituto per la storia del Risorgimento italiano. 
BUTRÓN, Gonzalo (2004). Nuestra Sagrada Causa. El modelo gaditano en la revolución piamontesa de 1821. Cádiz: Fundación Municipal de Cultura.

BUTRÓN, Gonzalo (2011). Liberté, nation et constitution. Le modèle révolutionnaire espagnol en Italie au début des années 1820. En Jean-Philippe LUIS (ed.). La guerre d'Indépendance espagnole et le libéralisme au XIXe. siècle. Madrid: Casa de Velázquez.

BUTRÓN, Gonzalo (2012). La inspiración española de la revolución piamontesa de 1821. Historia constitucional, 13, 73-97. http://www.historiaconstitucional.com

CALVO MARCOS, Manuel (1883). El régimen parlamentario en España en el siglo XIX. Madrid: El Correo.

CANDELORO, Giorgio (1956-1986). Storia dell'Italia moderna, 11 vol. Milano: Feltrinelli.

CAPOGRASSI, Antonio (1949). Gl'inglesi in Italia durante le campagne napoleoniche (lord W. Bentinck). Bari: Laterza.

CAPRA, Carlo (1989). Alle origini del moderatismo e del giacobinismo in Lombardia: Pietro Verri e Pietro Custodi. Studi storici, XXX, 4, 873-890.

CARR, Raymond (1978). Storia della Spagna 1808-1939, 2 vol. Firenze: La Nuova Italia.

CASINI, Tommaso (ed.) (1897). La rivoluzione di Milano dell'aprile 1814. Relazioni storiche di Leopoldo Armaroli e Carlo Verri. Roma: Dante Alighieri.

CHATEAUBRIAND, François-René de (1838), Congrès de Vérone; Guerre d'Espagne; Négociations; Colonies espagnoles, 2 vol. Paris: Delloye.

CIBRARIO, Luigi (1861). Notizie sulla vita di Carlo Alberto iniziatore e martire della indipendenza d'Italia. Torino: Eredi Botta.

CIBRARIO, Luigi (1865). Carlo Alberto iniziatore e martire della indipendenza italiana. Milano: Civelli.

COLlEGNO, Margherita di (1929). Memorie di Giacinto Provana di Collegno (1794-1816). Nuova Antologia, 1 dicembre, 28.

COLLETTA, Pietro (1861). Cenno storico sulla rivoluzione napoletana del 1820, in Opere inedite o rare, 2 vol., Napoli: Stamperia nazionale.

COLOMBO, Adolfo (1921). Il colloquio storico del 6 marzo 1821. Rassegna storica del Risorgimento, VIII, 278-318.

COLOMBO, Adolfo (1926). La rivolta della cittadella di Torino (12 marzo 1821). En Biblioteca di Storia Italiana Recente (1800-1870), vol. XI. La rivoluzione piemontese dell'anno 1821 (525-648). Torino: Bocca.

COLOMBO, Paolo (1998). Costituzione come ideologia. Le rivoluzioni italiane del 1820-21 e la costituzione di Cadice. En José María PORTILLO (ed.). La nazione cattolica. Cadice 1821: una costituzione per la Spagna (129 ss). Manduria: Lacaita. 
CORCIULO, Maria Sofia (1991). La stampa costituzionale napoletana e le modifiche alla Costituzione di Cadice. En Andrea ROMANO (ed.). Alle origini del costituzionalismo europeo. Messina: Presso l'Accademia.

CORCIUlO, Maria Sofia (2010). Una rivoluzione per la Costituzione (1820-'21). Agli albori del risorgimento meridionale. Pescara: ESA.

COSTA DE BEAUREGARD, Charles-Albert (1889). Prologue d'un règne. La jeunesse du roi Charles-Albert. Paris: Plon Nourrit.

COSTA DE BEAUREGARD, Charles-Albert (1890). Épilogue d'un règne. Milan, Novare et Oporto. Les dernières années du roi Charles-Albert. Paris: Plon Nourrit.

CROCE, Benedetto (1965). Storia del regno di Napoli. Bari: Laterza.

D'ANDREA, Diletta (2007). "If Sicily should become a BritishIsland». Sicilia e Gran Bretagna in età rivoluzionaria enapoleonica. Messina: Rino Labate Editore.

D'ANDREA, Diletta (2012). Gould Francis Leckie e la Sicilia,1801-1818. Napoli: Edizioni Scientifiche Italiane.

D’ANGELO, Michela (1998). La «Gazzetta Britannica» di Messina e la Costituzione siciliana del 1812. En Andrea ROMANO (ed.). Il modello costituzionale inglese e la sua recezione nell'area mediterranea tra la fine del '700 e la prima metà dell '800. Milano: Giuffré.

D'AZEGLIO, Massimo (1971). I miei ricordi, Torino, Einaudi.

DAUM, Werner (2007). Significato e eredità del decennio francese (e inglese) (1806-1815). Il Regno di Napoli e il Regno di Sicilia in una prospettiva di storia costituzionale comparata. Napoli: Istituto Italiano per gli Studi Filosofici.

DE FRANCESCO, Antonino (1996). La Costituzione di Cadice nella cultura politica italiana del primo Ottocento. En Antonino DE FRANCESCO. Rivoluzione e costituzioni. Saggi sul democratismo politico nell'Italia napoleonica, 1796-1821 (127 ss.). Napoli: ESI.

DE NICOLA, Carlo (1906). Diario napoletano dal 1798 al 1825, 3 vol. Napoli: Società Napoletana di Storia Patria.

DE SALVO, Patrizia (2009). Istruzione, stampa e opinione pubblica: influenze del costituzionalismo inglese, fra Cadice e Palermo. Spagna contemporanea, 36, 81-98.

DE SALVO, Patrizia (2010). Editori e fogli periodici nella Sicilia fra Sette e Ottocento: il caso di Messina. Brocar, 34, 33-48.

DE SALVO, Patrizia (2016). Sicilia inglesa. Una metáfora del constitucionalismo mediterráneo. Madrid: UAM.

DEGLI ALBERTI, Mario (1908) Dieci anni di storia piemontese (1814-1824). Nuove informazioni sulla Restaurazione e sul Ventuno in Piemonte ricavate dalle lettere inedite di Carlo Emanuele IV, Vittorio Emanuele I, Carlo Felice, Carlo Alberto ed altri. Torino: Bocca.

DEL CERRO, Emilio (1903). Fra le Quinte della Storia. Contributo alla storia del Risorgimento politico d'Italia. Torino: Bocca. 
DELFICO, Melchiorre (1820). Osservazioni sulla Rivoluzione di Napoli. Napoli: Tip. Luigi Nobile.

DES AMBROIS, Louis (1901). Notes et souvenirs inédits. Bologna: Zanichelli.

DITO, Oreste (1905). Massoneria, Carboneria ed altre società segrete nella storia del Risorgimento italiano. Torino-Roma: Roux e Viarengo.

EGIDI, Pietro (1926). I moti studenteschi di Torino nel gennaio 1821. En Biblioteca di Storia Italiana Recente (1800-1870), XI, La rivoluzione piemontese dell'anno 1821. Torino: Bocca.

FARINI, Luigi Carlo (1854-1859). Storia d'Italia dall'anno 1814 sino a' nostri giorni, 2 vol. Torino: Sebastiano Franco.

FERRANDO BADÍA, Juan (1959). La Costitución española de 1812 en los comienzos del Risorgimento. Roma-Madrid: C.S.I.C.

FERRANDO BADÍA, Juan (1962). Vicisitudes e influencias de la Constitución de 1812. Revista de Estudios Políticos, 126, 169-226.

FERRANDO BADÍA, Juan (1987). La Constitución española de 1812 y el Congreso de Verona. En Studi in onore di Paolo Biscaretti di Ruffía, 2 vol. (I, 359-399). Milano: Giuffré.

FERRANDO BADÍA, Juan (1991). Proyección exterior de la Constitución de 1812. Ayer, 1, 207-248.

FIORINI, Vittorio (ed.) (1900). Gli scritti di Carlo Alberto sul moto piemontese del 1821. Roma-Milano: Dante Alighieri.

FONTANA, Sandro (1968). La controrivoluzione cattolica in Italia: 1820-1830. Brescia: Morcelliana.

FUBINI LEUZZI, Maria (1980). Introduzione a Storia d'Italia e altri scritti editi e inediti di Cesare Balbo (9-78). Torino: UTET.

GALANTE GARRONE, Alessandro; DELLA PERUTA, Franco (eds.) (1979). La stampa italiana del Risorgimento. Roma-Bari: Laterza.

GALLAVRESI, Giuseppe (1912). La rivoluzione piemontese del 1821 nel carteggio d'un magistrato Giansenista. En Miscellanea di studi storici in onore di Antonio Manno, 2 vol. (II, 133). Torino: Officina Poligrafica Editrice Subalpina «O.P.E.S.»

GARDA, Pietro Alessandro (1879). La rivoluzione del 1821 Ricordi del Commend. Pietro Alessandro Garda. Ivrea: Curbis.

GENTZ, Friedrich von (1877). Dépêches inédites aux Hospodars de Valachie, 3 vol. Paris: Plon.

GIFFLENGA, Alessandro (1879). Memoriale del generale Gifflenga. En Antonio MANNO. Informazioni sul Ventuno in Piemonte. Firenze: Tipografia della Gazzetta d'Italia.

GIGLIO-TOS, Efisio (1906). Albori di libertà Gli Studenti di Torino nel '21. Torino: Streglio. 
GRAMSCI, Antonio (1975). Luzio e la storiografia tendenziosa e faziosa dei moderati in Quaderni dal carcere, ed. critica a cura di V. GERRATANA, quaderno 19, IV. Torino, Einaudi.

GUALTERIO, Filippo Antonio (1861). Gli ultimi rivolgimenti italiani. Memorie storiche, 6 vol. Napoli: Mirelli.

GUARDIONE, Francesco (1927). Di un nuovo assetto politico degli Stati italiani proposto da G.P. Vieusseux per il Congresso di Verona (1822). Rassegna Storica del Risorgimento, XIV, 507-524.

HALLER, Karl Ludwig von (1820). De la constitution des Cortès d'Espagne... Traduit de l'allemand par lui-même. Modène: Her. Soliani.

LEMMI, Francesco (1926) Il processo del Principe della Cisterna. En Biblioteca di Storia Italiana Recente (1800-1870), vol. XI, La rivoluzione piemontese dell'anno 1821. Torino: Bocca.

LEPRE, Aurelio (1967). La rivoluzione napoletana del 1820-1821. Roma: Editori Riuniti.

LIBERTI, Egidio (ed.) (1972). Tecniche della guerra partigiana nel Risorgimento. Firenze: Giunti Barbèra.

LUSERONI, Giovanni (2015). Ricerche bibliografiche sulle edizioni italiane della Costituzione di Cadice (1812-1850). En Fernando GARCÍA SANZ, Vittorio SCOTTI DOUGLAS, Romano UGOLINI, José Ramón URQUIJO GOITIA (eds.). Cadice e oltre: costituzione, nazione e libertà. La carta gaditana nel bicentenario della sua promulgazione (637-663). Roma: Istituto per la storia del Risorgimento italiano.

LUZIO, Alessandro (1923). Carlo Alberto e Giuseppe Mazzini. Torino: Bocca.

MANETTI, Giulio M. (1991). La costituzione inattuata, Pietro Leopoldo granduca di Toscana: dalla riforma comunitativa al progetto di costituzione. Firenze: Centro editoriale toscano.

MANFREDI, Michele (1932). Luigi Minichini e la Carboneria a Nola. Firenze: Le Monnier.

MANNO, Antonio (1879). Informazioni sul Ventuno in Piemonte. Firenze: Tipografia della Gazzetta d'Italia.

MANNO, Giuseppe (1866). Della fortuna delle Frasi. Torino: Unione Tipografico-editrice.

MARCOTTI, Giuseppe (1907). I flagelli del 1817. La rassegna nazionale, 1 ottobre 1907, 38-46.

MASI, Ernesto (1890). Il segreto di re Carlo Alberto. Bologna: Zanichelli.

MATURI, Walter (1969). Partiti politici e correnti di pensiero nel Risorgimento in Nuove questioni di storia del Risorgimento e dell'unità d'Italia, 2 vol. Milano: Marzorati. 
Memorie sulle società segrete dell'Italia meridionale e specialmente sui Carbonari Traduzione dall'inglese di Anna Maria Cavallotti (1904). Roma-Milano: Albrighi e Segati.

MERIGGI, Marco (1981). Liberalismo o libertà dei ceti? Costituzionalismo lombardo agli albori della Restaurazione. Studi storici, XXII, 2, 315-343.

METTERNICH, Clemens von (1880-1884). Mémoires, documents et écrits divers laissés par le prince de Metternich, 8 vol. Paris: Plon.

MORENO ALONSO, Manuel (1984). Las ideas políticas de «El Español». Revista de Estudios Políticos, 39, 65-106.

MORENO ALONSO, Manuel (1989). Las ideas constitucionales de Blanco-White. En Juan CANO BUESO (ed.). Materiales para el estudio de la Constitución de 1812 (521-543). Madrid: Tecnos.

MUÑOZ DE BUSTILLO, María del Carmen (2000). Cádiz como impreso. En La Constitución de 1812 (7-73). Sevilla: Fundación El Monte.

NEGRI, Paolo (1927). La rivoluzione piemontese del '21 nel carteggio della diplomazia pontificia. En La Rivoluzione piemontese del 1821 Studi e documenti raccolti da Teofilo Rossi e da Carlo Pio De Magistris, 2 vol. (II, 466-502). Torino: Soc. Tip. Monregalese.

ODORICI, Federico (1872). Il Conte Luigi Cibrario e i tempi suoi Memorie Storiche con documenti, Firenze, Civelli.

OMODEO, Adolfo (1940). La leggenda di Carlo Alberto nella recente storiografia. Torino: Einaudi.

OTTOLENGHI, Leone (1881). La vita e i tempi di Luigi Provana del Sabbione. Studio. Torino: Loescher.

OTTOLENGHI, Leone (1882). La vita e i tempi di Giacinto Provana di Collegno. Torino: Loescher.

PALMA, Alerino (1829). Difesa dei Piemontesi inquisiti a causa degli avvenimenti del 1821, con un invocazione ai ministri costituzionali. Bruxelles.

PALMA, Luigi (1895). Il tentativo Costituzionale del 1820 a Napoli. Nuova Antologia, XXX, 140, 467.

PASQUIER, Étienne-Denis (1894). Mémoires, 5 vol. Paris: Plon.

PASSAMONTI, Eugenio (1927). Prospero Balbo e la rivoluzione del 1821 in Piemonte. En Teofilo ROSSI, Carlo DEMAGISTRIS (eds.). La rivoluzione piemontese del 1821, 2 vol. (II, 190-348). Torino: Società Storica Subalpina.

PASSAMONTI, Eugenio (1930). Nuova luce sui processi del 1833 in Piemonte. Firenze: Le Monnier.

PASSERIN D'ENTRÈVES, Ettore (1940). La giovinezza di Cesare Balbo. Firenze: Le Monnier.

PECCHIO, Giuseppe (1821). Sei mesi in Ispagna nel 1821. Lettere di Giuseppe Pecchio a Ledi G.O. Madrid: Don Michele di Burgos. 
PECCHIO, Giuseppe (1822). Tre mesi in Portogallo nel 1822. Lettere di Giuseppe Pecchio a Ledi G.O. Madrid: Don Michele di Burgos.

PECCHIO, Giuseppe (1823). Anecdotes of the Spanish and Portuguese revolutions. London: Whittaker.

PECCHIO, Giuseppe (1978). Scritti politici. Roma: Istituto per la storia del Risorgimento italiano.

PEPE, Gabriele (1978). Considerazioni Istoriche e Politiche sulla Rivoluzione Napoletana, a cura di Renato LALLI, 2 vol. Isernia: Marinelli.

PEPE, Gugliemo (1847). Memorie del Generale Guglielmo Pepe intorno alla sua vita e ai recenti casi d'Italia scritte da lui medesimo, 2 vol. Parigi: Baudry.

PÉREZ GALDÓS, Benito (1984). Cádiz. Madrid: Alianza.

PERRERO, Domenico (1889). Gli ultimi Reali di Savoia del ramo primogenito ed il principe Carlo Alberto di Carignano. Torino: Casanova.

PIVANO, Silvio (1934). Un progetto inedito di costituzione in Piemonte nel 1821. Rassegna storica del Risorgimento, XXI, 1, 31-48.

PONS, André (1990). Blanco White et la crise du monde hispanique, 1808-1814. Paris: Université de Paris III-Sorbonne.

PONS, André (1992). Blanco White y la oposición a las Cortes de Cádiz: un ejemplo de recuperación política. Bulletin d'Histoire Contemporaine de l'Espagne, $15,41-69$.

PONS, André (2002). Blanco White y España. Oviedo: IFESXVIII.

PONS, André (2006). Blanco White y América. Oviedo: IFESXVIII.

PONS, André (2010). Epistolario y documentos. Oviedo: IFESXVIII.

PORTILLO, José María (1998). ¿Existía una antigua constitución española? El debate sobre el modelo inglés en España, 1806-1812. En Andrea ROMANO (ed.). Il modello costituzionale inglese e la sua recezione nell'area mediterranea tra la fine del '700 e la prima metà dell '800. (545-585). Milano: Giuffré.

PREZZOLINI, Giuseppe (1913). Introduzione a Giuseppe PECCHIO, Osservazioni semiserie di un esule in Inghilterra. Lanciano: R. Carabba.

QUEYPO DE LLANO, Giuseppe Maria, Conte di TORENO (1838). Storia della sollevazione, guerra e rivoluzione della Spagna. 2 vol. Milano: Bonfanti.

RENDA, Francesco (1963). La Sicilia nel 1812. Palermo: Sciascia.

RICOTTI, Ercole (1856). Della vita e degli scritti del conte Cesare Balbo. Rimembranze con documenti inediti. Firenze: Le Monnier.

RINIERI, Ilario (1902). I costituti del Conte Confalonieri e il Principe di Carignano. Torino: Streglio.

ROCCO, Lorenzo (1921). La stampa periodica napoletana delle rivoluzioni (17991820-1848-1860). Napoli: Lubrano.

RODOLICO, Niccolò (1931). Carlo Alberto principe di Carignano. Firenze: Le Monnier. 
RODOLICO, Niccolò (1936). Carlo Alberto negli anni di regno 1831-1843. Firenze: Le Monnier.

RODOLICO, Niccolò (1943). Carlo Alberto negli anni di regno 1843-1849. Firenze: Le Monnier.

ROMAGNANI, Gian Paolo (1988-1990). Prospero Balbo. Intellettuale e uomo di stato (1762-1837), I, Il tramonto dell'Antico Regime in Piemonte (1762-1800); II, Da Napoleone a Carlo Alberto (1800-1837). Torino: Deputazione Subalpina di Storia Patria.

ROMANO, Andrea (ed.) (1998). Il modello costituzionale inglese e la sua recezione nell'area mediterranea tra la fine del '700 e la prima metà dell '800. Milano: Giuffré.

ROMANO, Andrea (2004). Linfluenza della carta gaditana nel costituzionalismo italiano ed europeo. En Asdrúbal AGUIAR (coord.). La Constitución de Cádiz de 1812: hacia los orígenes del constitucionalismo iberoamericano y latino (351373). Caracas: Universidad Católica Andrés Bello.

ROMANO, Andrea (2015). La costituzione di Cadice nella penisola italiana: un disegno politico europeo?. En Fernando GARCÍA SANZ, Vittorio SCOTTI DOUGLAS, Romano UGOLINI, José Ramón URQUIJO GOITIA (eds.). Cadice e oltre: costituzione, nazione e libertà. La carta gaditana nel bicentenario della sua promulgazione (7-24). Roma: Istituto per la storia del Risorgimento italiano.

ROMEO, Rosario (1960). Storia del Piemonte, I. Torino: Casanova.

ROMEO, Rosario (1963). Dal Piemonte sabaudo all'Italia liberale. Torino: Einaudi. ROSSELLI, Carlo (1992). Opere scelte, II, Scritti dall'esilio-Dallo scioglimento della concentrazione antifascista alla guerra di Spagna (1934-1937). Torino: Einaudi.

ROSSELLI, John (1956). Lord William Bentinck and the British Occupation of Sicily: 1811-1814. Cambridge: Cambridge University Press.

SAITTA, Armando (1950). Filippo Buonarroti. Contributo alla storia della sua vita e del suo pensiero, 2 vol. Roma: Edizioni di Storia e Letteratura.

SALATA, Francesco (ed.) (1940-1941). I costituti di Federico Confalonieri, 4 voll., i primi tre Bologna: Zanichelli; il quarto Achille GIUSSANI (ed.) (1956). Roma: Ist. Storico Italiano per l'età moderna e contemporanea.

SALVATORELLI, Luigi (1963). Pensiero e azione del Risorgimento. Torino: Einaudi. SANTAROSA, Santorre di (1920a). La Rivoluzione Piemontese nel 1821 coi ricordi di V. Cousin sull'autore, a cura di Alessandro LUZIO. Torino: Paravia.

SANTAROSA, Santorre di (1920b). Delle speranze degli italiani. Adolfo COLOMBO (ed.). Milano: Casa ed. Risorgimento R. Caddeo \& C.

SAULI D'IGLIANO, Ludovico (1908). Reminiscenze della propria vita, a cura di Giuseppe OTTOLENGHI, 2 vol. Roma-Milano: Albrighi e Segati.

SCAGLIA, Giovanni Battista (1975). Cesare Balbo. Il Risorgimento nella prospettiva storica del "progresso cristiano». Roma: Studium. 
SCAGLIA, Giovanni Battista (1989). Cesare Balbo. Lindipendenza d'Italia e l'avvenire della cristianità. Roma: Studium.

SCOTTI DOUGLAS, Vittorio (2000). Spagna 1808: la genesi della guerriglia moderna. 1. Guerra irregolare, "petite guerre», «guerrilla». Spagna contemporanea, 18, 9-31.

SCOTTI DOUGLAS, Vittorio (2001). Spagna 1808: la genesi della guerriglia moderna. 2. Fenomenologia della guerriglia spagnola e suoi riflessi internazionali. Spagna contemporanea, 20, 73-167.

SCOTTI DOUGLAS, Vittorio (2007). Carlo Bianco, l'«inventore» della guerra per bande. En Giovanni Maria CAGLIERIS, Vittorio SCOTTI DOUGLAS (eds.). Dal Risorgimento alla Resistenza. Carlo Bianco di St. Jorioz e la lotta per bande. Barge (25-75). Saluzzo: Fusta.

SCOTTI DOUGLAS, Vittorio (2009). Gabriele Pepe «rivoluzionario» moderato e coerente. En Vittorio SCOTTI DOUGLAS (ed.). Dal Molise alla Catalogna. Gabriele Pepe e le sue esperienze nella Guerra del francès. Testi inediti e lettere. 2 vol (I, 75-120). Campobasso: Arti Grafiche la Regione.

SCOTTI DOUGLAS, Vittorio (2013). Il moderato e la guerra per bande. Alcuni inediti di Cesare Balbo sulla guerriglia antinapoleonica spagnola. En Nicola LABANCA (ed.). Forze armate. Cultura, società, politica (113-131). Milano: Unicopli.

SCOTTI DOUGLAS, Vittorio (2015). Due rivoluzioni, due protagonisti, due visioni: Gabriele Pepe e Napoli nel 1820, Cesare Balbo e Torino nel 1821. En Fernando GARCÍA SANZ, Vittorio SCOTTI DOUGLAS, Romano UGOLINI, José Ramón URQUIJO GOITIA (eds.). Cadice e oltre: costituzione, nazione e libertà. La carta gaditana nel bicentenario della sua promulgazione (491-525). Roma: Istituto per la storia del Risorgimento italiano.

SEGRE, Arturo (1926). L'episodio di S. Salvario (11 marzo 1821). En Biblioteca di Storia Italiana Recente (1800-1870), XI, La rivoluzione piemontese dell'anno 1821. Torino: Bocca.

SELLA, Domenico; CAPRA, Carlo (1984). Il Ducato di Milano dal 1535 al 1796. Vol XI di GALASSO, Giuseppe (dir.) (1986-1987). Storia d'Italia, 24 vol. Torino: UTET.

SFORZA, Giovanni (1921). Velleità costituzionali della Duchessa di Lucca. Rassegna storica del Risorgimento, VIII, 1-24.

SPADONI, Domenico (1910). Una trama e un tentativo rivoluzionario dello Stato Romano nel 1820-21. Roma-Milano: Albrighi e Segati.

SPINI, Giorgio (1958). A proposito di «circolazione delle idee» nel Risorgimento: la «Gazzetta Britannica» di Messina. En Miscellanea in onore di Roberto Cessi, 3 vol (III, 17-34). Roma: Ed. di Storia e Letteratura.

SPINI, Giorgio (1978). Presentazione. En Raymond CARR, Storia della Spagna. Firenze: La Nuova Italia. 
SPINI, Giorgio (1990a) Incontri europei e americani col Risorgimento. Firenze: Vallecchi.

SPINI, Giorgio (1990b [1950]). Mito e realtà della Spagna nelle rivoluzioni italiane del 1820-1821. En Giorgio SPINI. Incontri europei e americani col Risorgimento (37-196). Firenze: Vallecchi.

Storia della rivoluzione di Spagna tradotta dall'originale inglese (1817). Pisa: Capurro. SUÁREZ VERDAGUER, Federico (1982). Las Cortes de Cádiz. Madrid: RIALP.

SUÁREZ VERDAGUER, Federico (1987). La crítica liberal a la Constitución de 1812. Gades 1812-1987, 16, 37-55.

TABARRINI, Marco (ed.) (1877). Scritti editi e inediti di Gino Capponi, 2 vol. G. Barbèra: Firenze.

TALIENTO, Esther (1920). Appunti storico-bibliografici sulla stampa periodica napoletana, durante le rivoluzioni del 1799 e 1820-1821. Bari: S.T.E.B.

THAON DI REVEL, Ignazio (1871). Mémoires sur la guerre des Alpes et les événements en Piémont, pendant la révolution française. Turin: Bocca.

TITONE, Virgilio (1936). La costituzione del 1812 e l'occupazione inglese della Sicilia con un saggio sul concetto di rivoluzione. Bologna: Cappelli.

TORENO (Conte di), QUEYPO DE LLANO, Giuseppe Maria (1838) Storia della sollevazione, guerra e rivoluzione della Spagna, 2 vol. Milano: Bonfanti.

TORTA, Carlo (1908). La rivoluzione piemontese nel 1821. Roma-Milano: Società Editrice Dante Alighieri.

TRAMPUS, Antonio (2015). Le costituzioni italiane prima di Cadice. En Fernando GARCÍA SANZ, Vittorio SCOTTI DOUGLAS, Romano UGOLINI, José Ramón URQUIJO GOITIA (eds.). Cadice e oltre: costituzione, nazione e libertà. La carta gaditana nel bicentenario della sua promulgazione (161-172). Roma: Istituto per la storia del Risorgimento italiano.

VARELA SUANZES-CARPEGNA, Joaquín (1993). Un precursor de la monarquía parlamentaria: Blanco-White y «El Español» (1810-1814). Revista de Estudios Políticos, 79, 101-120.

VERRI, Pietro (1854). Scritti vari di Pietro Verri ordinati da Giulio Carcano, 2 vol. Firenze: Le Monnier.

VERUCCI, Guido (1968). I cattolici e il liberalismo. Dalle «Amicizie cattoliche» al modernismo. Padova: Liviana.

ZOBI, Antonio (1852). Storia civile della Toscana dal MDCCXXXVII al MDCCCXLVIII, 5 vol. Firenze: Molini. 